BNWL -1153

UC-80, Reactor

Technology

\title{
PCTR MEASUREMENT OF THE REACTIVITY EFFECTS OF $0.8 \%$ ENRICHED URANIUM FUEL IN A GRAPHITE MODERATED LATTICE WITH VARIOUS AMOUNTS OF WATER COOLANT AND FLOODING
}

By
A. D. Vaughn and

M. J. Kilgore

Reactor Physics Department Fhysics and Engineering Division

August 1969

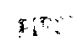

is

BATTELLE MEMORIAL INSTITUTE PACIFIC NORTHWEST LABORATORIES

RICHLAND, WASHINGTON 99352 
TABLE OF CONTENTS

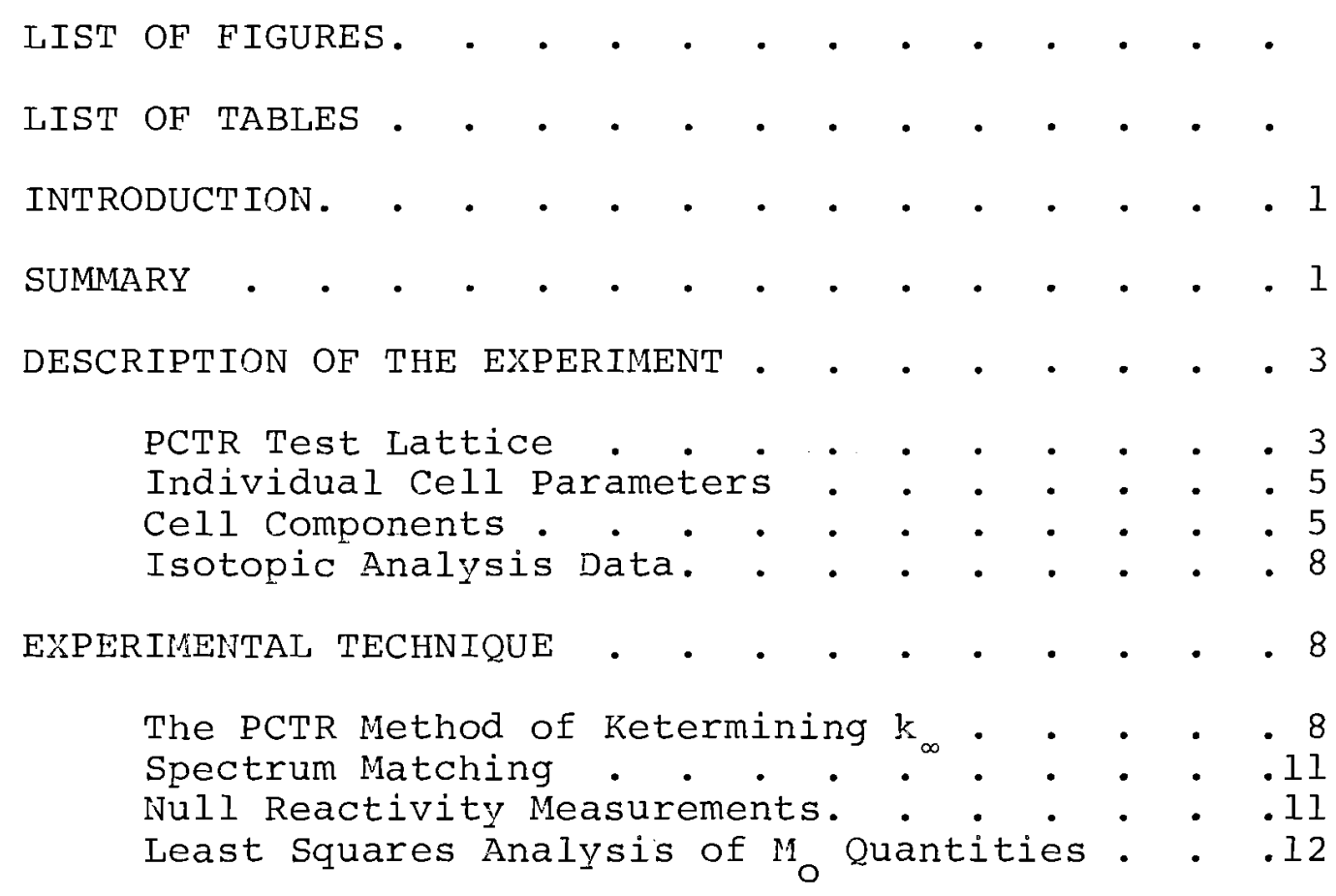

RELATIVE REACTION RATE AND $k_{\infty}$ DETERMINED BY NULL

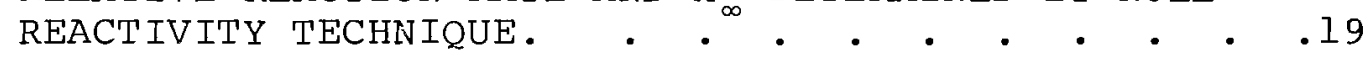

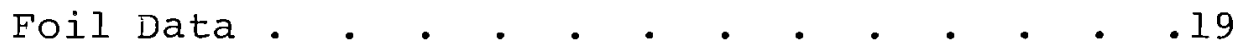

Corrections to Foil and Pin Data . . . . .22

Comparison of Measured Foil Activities with

Thermos Calculations . . • . • • . . . . 26

Neutron Cross Sections. . . . . . . . . . . . . . 6

l/V Utilization. . . . . . . . . . . . . . . .30

Determination of $k_{\infty} \cdot$ •

$k$ DETERMINED FROM ADJOINT WEIGHTED CROSS SECTION

TE̊CHIIQUE. • • • • • • • • • • • • • • . 38

Adjoint Weighted Cross Section Parameters . . 38

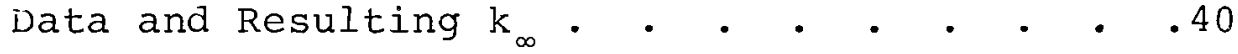

COMPARISON OF ACTUAL WATER FLOODING WITH SIMULATED

FLOODING • • • • • • • • • • • • • • • • • 40

Description . . . . . . . . . . . . .40

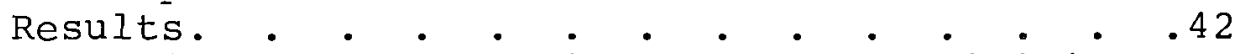

Comparison of Sub-Cadmium Measured Activities

With THERMOS Calculations for Water Flooded

Conditions. . . . . . . . . . . . . .44

Cross Sections and Utilizations. . . . . .47 


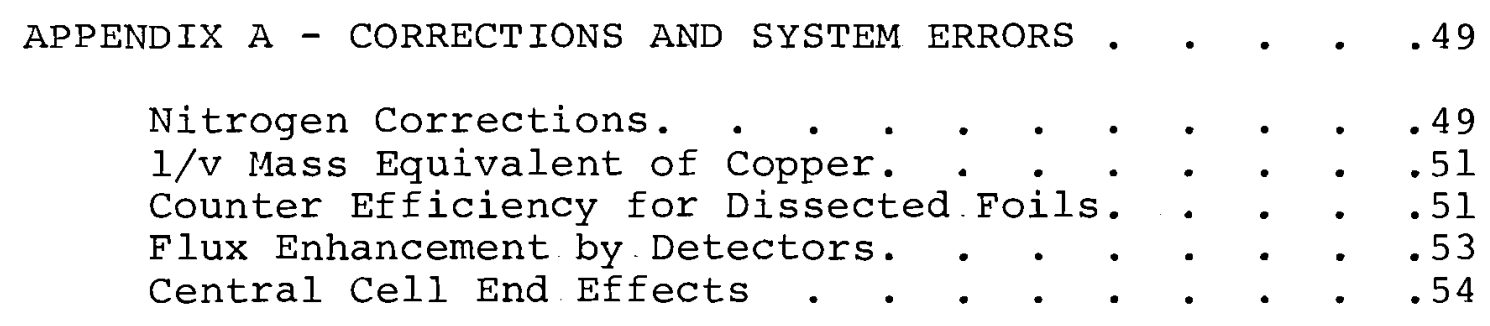




\section{LIST. OF FIGURES}

1 PCTR Test Lattice with Moderator used for Various Flooding Measurements. . . . . . . . . . . 4

2 Drawing of Individual cell (Front Face Plane). . . 6

3 Center Test cell with Simulated Process channel Flooding (Polyethlene) and Simulated Gas Vent Flooding (Lucite). . . . . . . . . . . 7

4 Central Test cell Being Removed from PCTR Test Lattice . . . . . . . . . . . . . .13

5 Graphic Results of Least Squares Analysis of Reactivity and Cadmium Ratio Data With Normal Coolant Conditions. . . . . . . . . . . . . .

6 Graphic Results of Least Squares Analysis of Reactivity and Cadmium Ratio Data With Simulated Flooding Conditions Around Process Tube. . . . 15

7 Graphic Results of Least Squares Analysis of Reactivity and Cadmium Ratio Data With Simulated Flooding Conditions Around Process Tube and in Gas vents. . . . . . . . . . . . . . . . . . . .

8 Front Face Plan of center Test cell. Showing Foil and Pin Locations for Radial Flux Transverse. . .20

9 Center Test cell with Associated Foil Holders and Separable Fuel Element. . . . . . . . . . . . 1

10 Axial Traverse Data of Bare Foils on Outer Cell with Normal Coolant Conditions. . . . . . . .24

11 Radial Flux Plots Derived by Experiment and THERMOS Calculations (Normal Coolant Conditions). .27

12 Radial Flux Plots Derived by Experiment and THERMOS Calculations I Simulated Process Channel Flooding):

13 Radial Flux Plots Derived by Experiment and THERMOS Calculations ( Simulated Process Channel and Gas Vent Floodingl . . . . . . . . . . 29

14 Center cell and Aluminum Tank Used for the Experimental Measurement of Actual Water Flooding Efoects 
BNWL -1153

XVIII Experimental 1/V Absorption Rates and Utilizations (water Flooding Conditions). . . .48

XIX Corrections to $k_{\infty}$ for cell End Effects. . . .55 
BNWL-1153

PCTR MEASUREMENT OF THE REACTIVITY EFFECTS

OF $0.8 \%$ ENRICHED URANIUM FUEL IN A GRAPHITE MODERATED LATTICE WITH VARIOUS

AMOUNTS OF WATER COOLANT AND FLOODING

A. D. Vaughn and M. J. Kilgore

\section{INTRODUCTION}

Neutronic parameters with various water coolant and flooding conditions in a 7-1/2 inch square pitch graphite lattice containing $0.8 \%$ enriched uranium metal fuel have been measured in the Physics Constants Test Reactor.

This report describes the techniques and the experimental measurements necessary to derive the infinite medium neutron multiplication factor in four cases; namely, two different simulated flooding conditions, normal cell conditions, and the dry cell. Finally, the neutronic parameters of an actual water flooded cell were measured and some preliminary results are derived which provide a comparison of the effects of actual water flooding with simulated flooding. All measurements were made at room temperature.

\section{SUMMARY}

The measurement of $\mathrm{k}_{\infty}$ in the experimental analysis followed two techniques; namely, the null reactivity measurement technique ${ }^{(1)}$ and the excess neutron adjoint weighted cross section technique ${ }^{(2)}$. The results are listed in Table I for all the matched cell conditions.

Several perturbation measurements were taken which differ slightly from the basic cell conditions listed in Table $I$. For the perturbation results, measurements were taken on the central test cell; however, the buffers were at slightly different conditions. These measurements are helpful in estimating the reactivity effects due to partial changes in a reactor lattice and are useful for experimental verification of calculational 
TABLE I. Lattice Parameters Determined From PCTR Measurements 10.8 wto Enriched Uranium Fuel - 7.5 Inch Lattice Pitch)

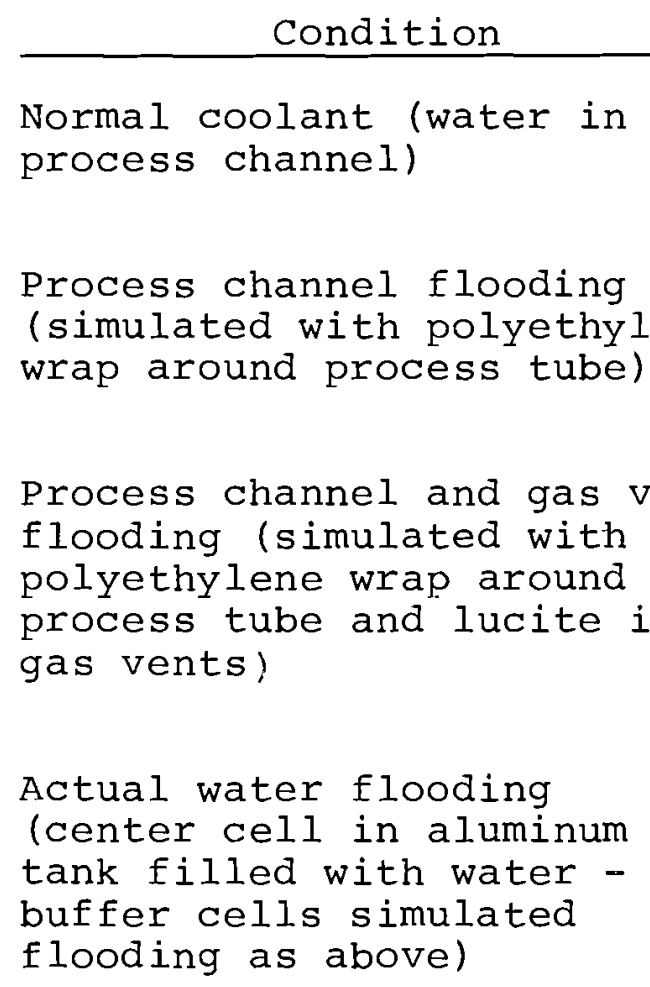

Dry Cells
Thermal Util. Air Atmosphere

\section{$0.933 \pm 0.011$}

$0.888 \pm 0.001$

$0.852 \pm 0.010$

$1.0014 \pm 0.0038$

$1.0065 \pm 0.0033$

$1.0071 \pm 0.0034$

k (Null React.

$0.9853 \pm 0.0035$

$0.9853 \pm 0.0035$ Mea surement) *

$0.9848 \pm 0.0035$

$0.806 \pm 0.010$

$0.9672 \pm 0.0030$

$0.9693 \pm 0.0030$

$1.0003 \pm 0.0038$ $\sqrt{2}+x^{2}$

.

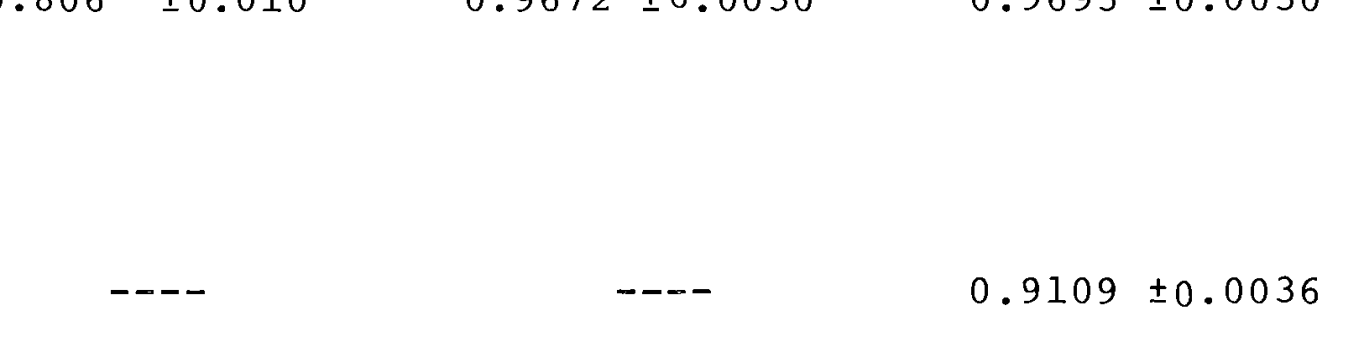

\footnotetext{
* Excess neutron production adjoint weighted cross section measurement (2).
} 
techniques. The results of these measurements, listed in Table II are in terms of the mass of copper necessary to achieve unit multiplication.

TABLE II. Measured Mass of Copper Necessary To Achieve unit Multiplication

\begin{tabular}{|c|c|}
\hline & $\begin{array}{c}\text { Mass of Copper } \\
\text { (grams) }\end{array}$ \\
\hline $\begin{array}{l}\text { Normal coolant case with water in process tube } \\
\text { Water in process tube and } 295 \mathrm{cc} \text { water in } \\
\text { center cell moderator (buffer cells with } \\
\text { normal coolant and no wacer in graphite }\end{array}$ & $\begin{array}{l}-54.8 \pm 0.7 \\
+152 \pm 4\end{array}$ \\
\hline $\begin{array}{l}\text { Water in process tube and polyethylene wrap } \\
\text { around process tube (buffer cells with } \\
\text { normal coolant and no polyethylene wrap) }\end{array}$ & $+450 \pm 5$ \\
\hline $\begin{array}{l}\text { Water in process tube and simulated flooding } \\
\text { in hole bar with polyethylene wrap around } \\
\text { process tube 'all cells) }\end{array}$ & $+63.0 \pm 0.8$ \\
\hline $\begin{array}{l}\text { Water in process tube and simulated flooding } \\
\text { in hole bar with polyethylene wrap around } \\
\text { process tube and simulated flooding in gas } \\
\text { vents with lucite }(\exists 1 . \mathrm{cells})\end{array}$ & $+46 \pm 4$ \\
\hline All cells dry & $-368 \pm 7$ \\
\hline One cell dry - buffers with normal coolant & $-211 \pm 5$ \\
\hline Vater flooded center cell and simulated & $-97 \pm 2$ \\
\hline
\end{tabular}

\section{DESCRIPTION OF THE EXPERIMENT}

PCTR Test Lattice

The test lattice was constructed with specially cut graphite moderator blocks arranged on 7.5 inch centers and stacked in a $5 \mathrm{x} 5$ array in the test cavity of the Physics constants Test Reactor (PCTR). A photograph of this arrangement is shown in Figure 1 and depicts the driver arrangement necessary to achieve critical with the test lattice in a normal condition, that is, with coolant in the process tube and gas vents containing air. 


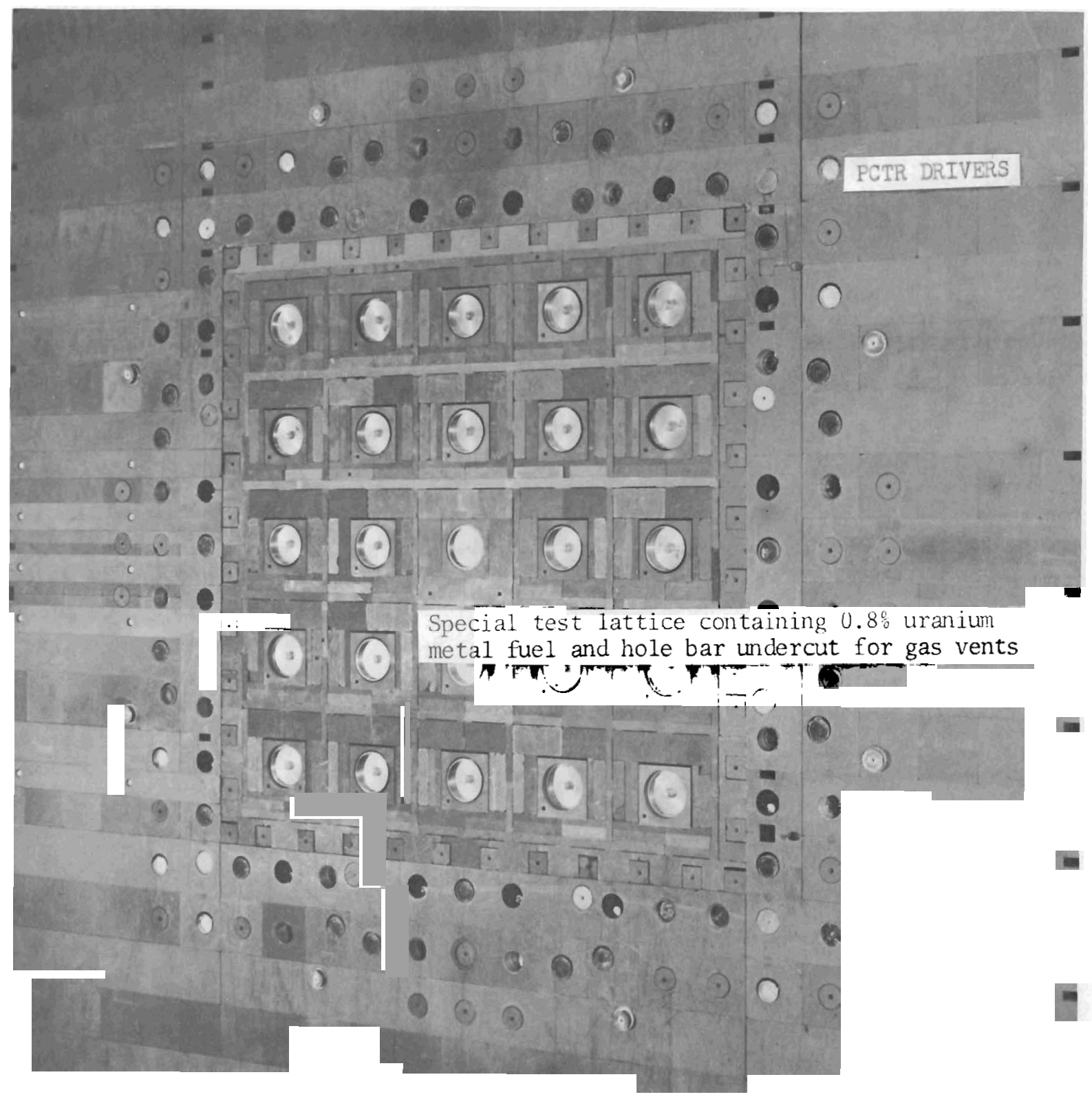

FIGURE 1. PCTR Test Lattice with Moderator used for various Flooding Measure ments 
BNWL-1153

Individual Cell parameters

The test cells were specifically designed to permit the addition of simulated flooding materials at strategic locations. The hole bar containing a 3.0 inch O.D. hole for the process tube was undercut to make gas vents which would normally be used to dry the lattice in an operating reactor but which would be flooded in the event of a process tube rupture.

Likewise, the process tube channel in the hole bar was enlarged sufficiently to permit the addition of a flooding simulator between the process tube and the graphite. These dimensions are better illustrated in Figure 2 which depicts the front face plane of an individual cell in the test lattice.

The 7.5 inch lattice block was undercut $0.020^{\prime \prime}$ in specific locations for the addition of copper strip which are used as neutron absorber in the experimental measurements with the poison technique. In this experiment the strips were 2.5 inches in width and therefore two cuts were made on each face of a test cell. These cuts are not depicted in Figure 2.

\section{Cell Components}

The fuel was metallic uranium containing 0.8 wt\% $\mathrm{U}^{235}$ enrichment, aluminum cladding, and contained in a zirconium process tube.

Water was always used as coolant in the process tube because the tube could be sealed; however, polyethylene was wrapped around the process tube to simulate process channel flooding and lucite was placed in the gas vents to simulate gas vent flooding. Figure 3 shows the arrangement of polyethylene and lucite in the central test cell.

The fuel element is nominally 8.870 inches in length and this includes a 0.230 inch thick end cap at each end. Therefore the center test cell used for the reactivity measurements was two complete fuel elements including their end caps. The front and rear buffers were each a single fuel element which was 


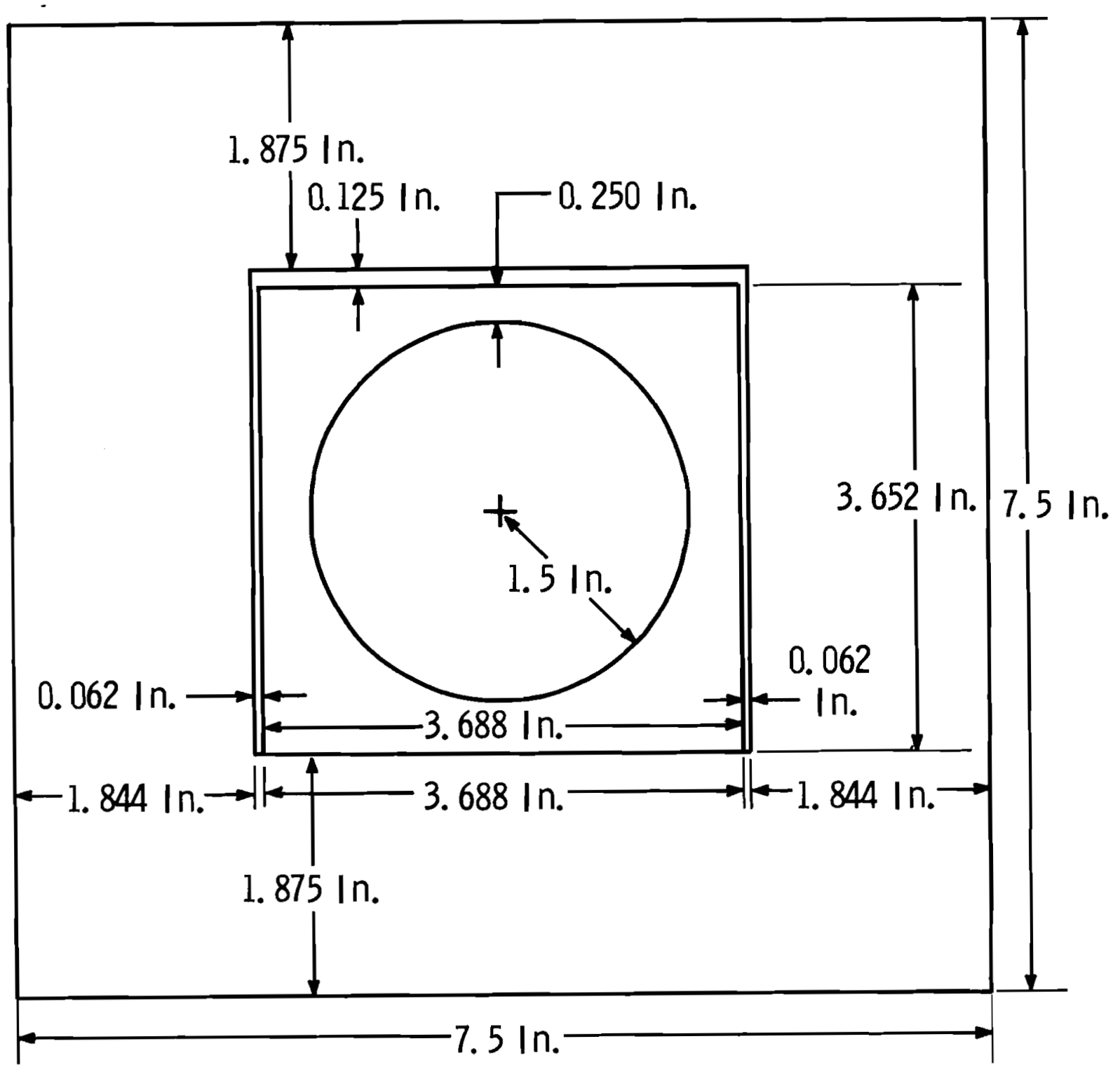

FIGURE 2. Overbore cell Dimensions (Front Face Plane) 
sufficient to achieve a matched neutron incident spectrum on the center test cell and not exceed the 37.5 inch depth of the PCTR test cavity.

This fuel was chosen because of its larger diameter and correspondingly higher fuel to moderator ratio region.

Details of the center test cell are listed in Table III and Table IV for normal coolant conditions and simulated flooding conditions, respectively.

Isotopic Analysis Data

It is standard practice to obtain an isotopic analysis of the fuel used in an experiment in order that exact absorption rates may be derived from the data. The results of this analysis are listed in Table $V$.

\section{EXPERIMENTAL TECHNIQUE}

The PCTR Method of Determining $k_{\infty}$

The general techniques for determining the infinite medium neutron multiplication factor $\left(\mathrm{k}_{\infty}\right)$ for test lattices in the Physical. Constants Test Reactor (PCTR) are discussed in Reference 5. A summary of this method is included here to make the data which follows more meaningful. Basically, the PCTR experiment follows these procedures:

Spectrum matching which is the adjustment of the neutron energy spectrum so that it is identical to an infinite array of test cells.

Neutron absorber measurements to determine the amount of neutron absorber (copper) required to achieve unit multiplication in the test cell. Measurement of the relative reaction rates of the components of the test cell in both the lattice reduced to unit multiplication with copper and the lattice without the copper added. 
TABLE III. Geometry and Parameters of Center Cell Containing water coolant

\begin{tabular}{|c|c|c|c|c|c|}
\hline Region & Isotope & Radius $(\mathrm{cm})$ & $\begin{array}{l}\text { Densitfy } \\
\mathrm{gm} / \mathrm{cm}^{3}\end{array}$ & Mass (gm) & $\begin{array}{c}\text { Volume } \\
\mathrm{cm}^{3}\end{array}$ \\
\hline Fuel & $\begin{array}{l}235 \mathrm{U} \\
238 \mathrm{U} \\
\mathrm{Al} \text { (caps) }\end{array}$ & 1.102 & $\begin{array}{l}17.570^{(2)} \\
0.140^{(2)}\end{array}$ & $\begin{array}{r}3 \quad 020.463 \\
24.164 \\
2 \quad 996.300 \\
24.071\end{array}$ & $\begin{array}{r}171.909 \\
162.994 \\
8.915\end{array}$ \\
\hline Fuel Clad & Aluminum & 1.214 & 2.70 & 99.144 & 36.720 \\
\hline Water & $\begin{array}{l}\text { Hydrogen } \\
\text { Oxygen } \\
\text { Al (supports) }\end{array}$ & 1.567 & $\begin{array}{l}0.992^{(3)} \\
0.0225\end{array}$ & $\begin{array}{r}137.809 \\
15.435 \\
122.374 \\
3.127\end{array}$ & $\begin{array}{r}138.967 \\
137.809 \\
1.158\end{array}$ \\
\hline Fuel clad & Aluminum & 1.681 & 2.70 & 141.525 & 52.417 \\
\hline Fuel & $\begin{array}{l}235 \mathrm{U} \\
238 \mathrm{U} \\
\mathrm{Al} \text { (caps) }\end{array}$ & 3.000 & $\begin{array}{l}17.570^{(2)} \\
0.140^{(3)}\end{array}$ & $\begin{array}{ll}15 & 356.534 \\
& 122.852 \\
15 & 233.682 \\
& 122.340\end{array}$ & $\begin{array}{r}874.016 \\
828.705 \\
45.311\end{array}$ \\
\hline Fuel Clad & Aluminum & 3.113 & 2.70 & 264.020 & 97.785 \\
\hline Water & $\begin{array}{l}\text { Hydrogen } \\
\text { oxygen } \\
\text { Al (supports) }\end{array}$ & 3.368 & $0.992^{(3)}$ & $\begin{array}{r}231.620 \\
25.941 \\
205.679 \\
3.907\end{array}$ & $\begin{array}{r}233.068 \\
1.448\end{array}$ \\
\hline Process Tube & zirconium & 3.482 & 6.40 & 707.481 & 110.544 \\
\hline Air & $\begin{array}{l}\text { Nitrogen } \\
\text { Oxygen }\end{array}$ & 3.810 & $1.293 \times 10^{-3}$ & $\begin{array}{l}0.044 \\
0.034 \\
0.010\end{array}$ & 338.580 \\
\hline Moderator & $\begin{array}{l}\text { Carbon } \\
\text { Nitrogen } \\
\text { Oxygen }\end{array}$ & $5.240^{(1)}$ & 1.770 & $\begin{array}{rr}3 & 242.250 \\
3 & 242.250 \\
& 0.360 \\
& 0.109\end{array}$ & 1831.999 \\
\hline Air & $\begin{array}{l}\text { Nitrogen } \\
\text { Oxygen }\end{array}$ & $5.418^{(1)}$ & $1.293 \times 10^{-3}$ & $\begin{array}{l}0.349 \\
0.268 \\
0.081\end{array}$ & 269.564 \\
\hline Moderator & $\begin{array}{l}\text { Carbon } \\
\text { Nitrogen } \\
\text { Oxygen }\end{array}$ & $10.747^{(1)}$ & 1.627 & $\begin{array}{rr}19 & 836.900 \\
19 & 836.900 \\
& 3.473 \\
& 1.049\end{array}$ & 12194.448 \\
\hline $\begin{array}{ll}\text { (1) Cylindri } & \text { Cyced } \\
\text { (2) Reduced } & \text { Reduced }\end{array}$ & $\begin{array}{l}\text { lius. } \\
\text { because of alt } \\
\text { because of alu }\end{array}$ & $\begin{array}{l}\text { ad caps. } \\
\text { dpports. }\end{array}$ & & & \\
\hline
\end{tabular}


TABLE IV. Geometry and Parameters of center cell with simulated Flooding conditions

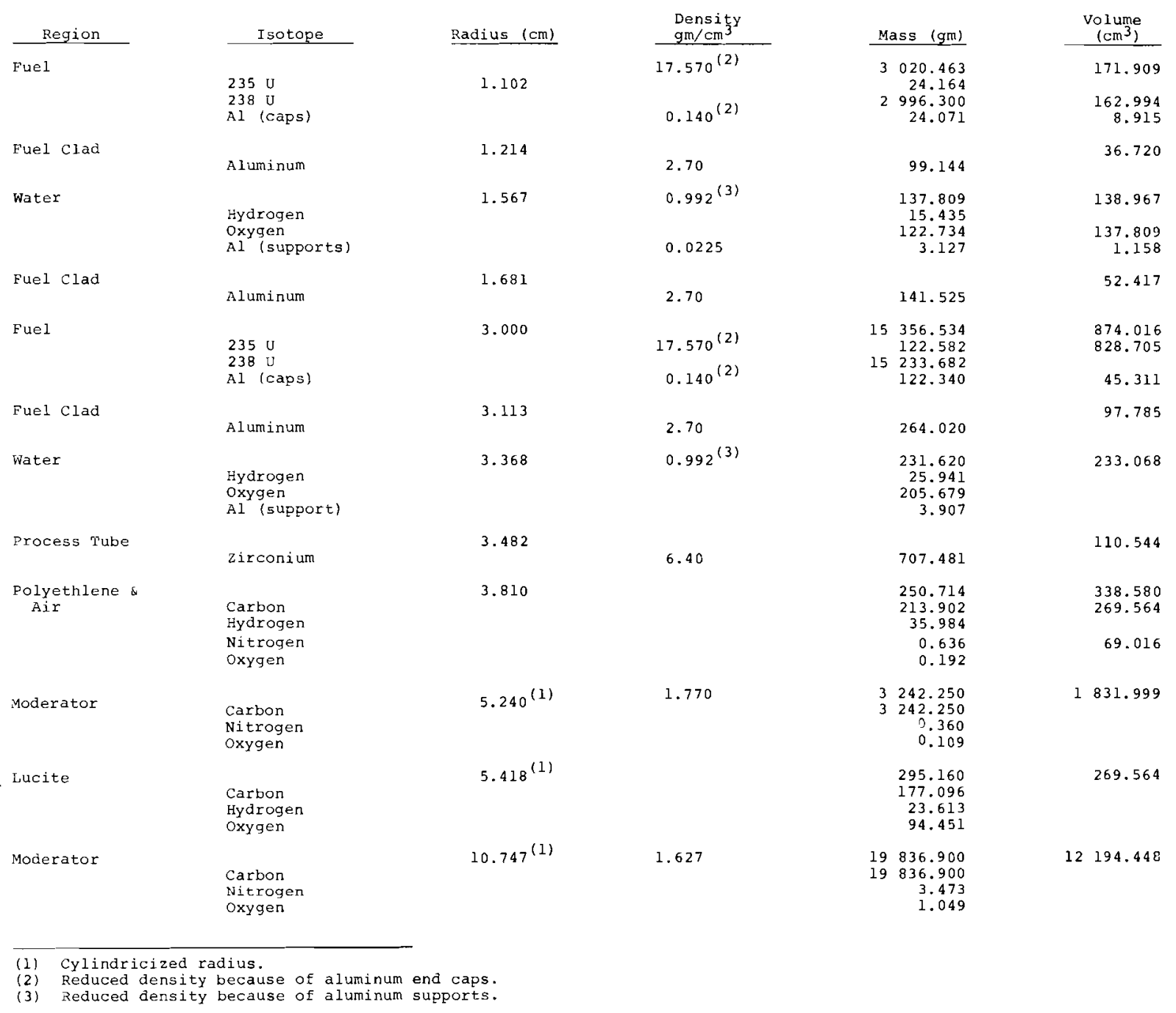

TABLEV. Isotopic Analysis Data of Fuel $(a)$

$\begin{array}{lc}\text { Isotope } & \frac{\text { atz }}{234 \mathrm{U}} \\ 235 \mathrm{U} & 0.0070 \pm 1 \\ 236 \mathrm{U} & 0.8056 \pm 30 \\ 238 \mathrm{U} & 0.0405 \pm 3\end{array}$

(a) Reported by C.R. Lagergren. 
effect on the reactor as on an empty cavity. In a properly poisoned cell the neutron absorptions balance the neutron productions. The central test cell. which was the test cell for the null reactivity measurements is shown being removed from the PCTR test lattice in Figure 4. Short end buffer cells enclose the central cell along the long axis. slots are provided in the lattice for the insertion of copper poison strips at the cell boundaries.

A reactivity series was completed for each loading for which the cadmium ratio of gold foils was measured. The basic technique has been simplified to the equation below:

$$
\mathbb{1}_{0}=\frac{\rho \text { cell in }-\rho \operatorname{cell} \text { out }}{\text { Units of reactivity per gram of absorber }}+\mathrm{M}_{\mathrm{cu}}^{\text {boundary }}
$$

where $\mathrm{M}_{\mathrm{Cu}}^{\text {boundary }}=$ Mass of copper on the cell boundaries;

$\rho$ cell in = PCTR reactivity with cell in;

$\rho$ cell out $=$ PCTR reactivity with cell out, corrected to exclude nitrogen effects.

It can be readily seen that the reactivity worth of the center test cell and of the absorber will change as the neutron spectrum changes. By making sufficient changes in the flux modifiers and taking adequate reactivity measurements, it is possible to extrapolate to the exact neutron absorber requirements for the matched spectrum conditions.

The differences in the cadmium ratio values and the respective measured masses of neutron absorber are listed in Table VI for all the different test lattices of this experiment. Least Squares Analysis of $M_{0}$ Quantities

The data listed in Table VI was analyzed via a least squares derivation of the linear relationship between the quantity (CTR-RD) and the measured $M_{0}$ for each cell condition. The results of this analysis are shown in Figures 5,6 and 7 which illustrate the 


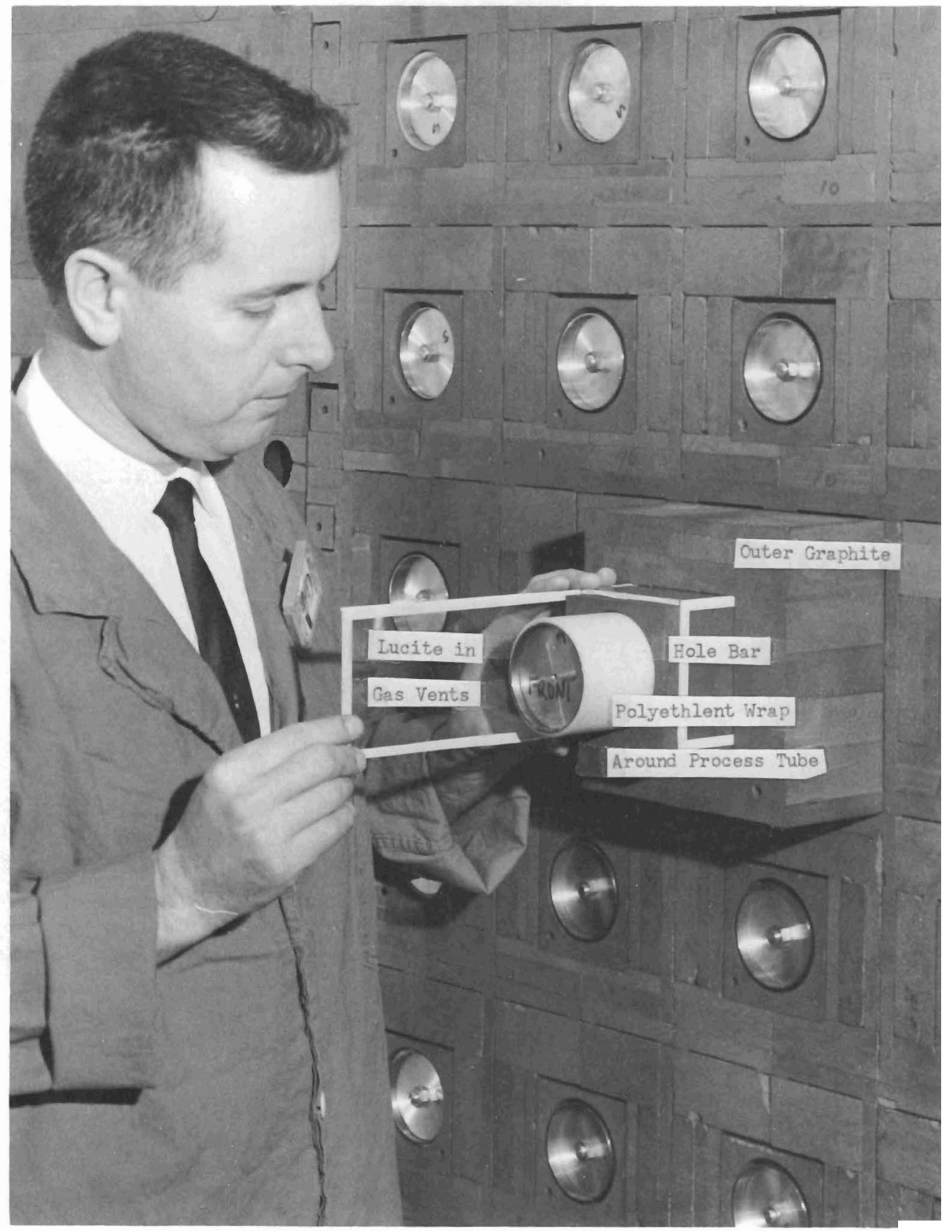

FIGURE 3. Center Test cell with Simulated Process channel Flooding (Polyethlene) and Simulated Gas Vent Flooding (Lucite) 
Measurement of the neutron leakage ratio from the test cell in order to determine the value of $\mathrm{k}_{\infty}$ from the excess neutron adjoint weighted cross section.

Spectrum Matching

The neutron energy distribution was inferred by measuring cadmium ratios of 0.005 inch thick gold foils and comparing the cadmium ratio in the center test cell with the values obtained at an equivalent location in a buffer region. The gold, when covered with cadmium, is activated almost entirely by neutrons in a narrow energy region around $4.9 \mathrm{ev}$. The large number of foils necessary for this measurement usually have slightly different thicknesses and therefore the cadmium ratios must be corrected to a standard foil thickness using experimental data published by R. A. Bennett. (6)

A weighted average $(\overline{R D})$ of the cadmium ratio of the buffer cell locations was computed for comparison with the cadmium

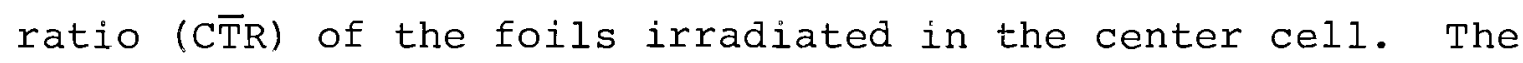
weighting used was the inverse of the linear distance, center to center, from a buffer cell to the center cell. The specific criteria for flux match is defined as the equivalence of $\mathrm{C} \overline{\mathrm{T}} \mathrm{R}$ and $\overline{\mathrm{RD}}$.

It is impractical to achieve an exact equivalence between the buffer cells and center test cell; however,. it is important to make several driver and flux modifier changes in order to determine the sensitivity of the measured mass of neutron absorber $\left(M_{0}\right)$ necessary to achieve unit neutron multiplication with respect to changes in the neutron spectrum. This is usually a function of the difference between the average cadmium ratios measured in the buffer cells and center cell. Therefore at each loading change, a series of reactivities are measured, called null reactivity measurements, to determine the quantity $\mathrm{M}_{\mathrm{O}}$.

\section{Nul1. Reactivity Measurements}

The null reactivity technique depends on: the observation that a properly poisoned cell will have the same reactivity 
BNWL-1153

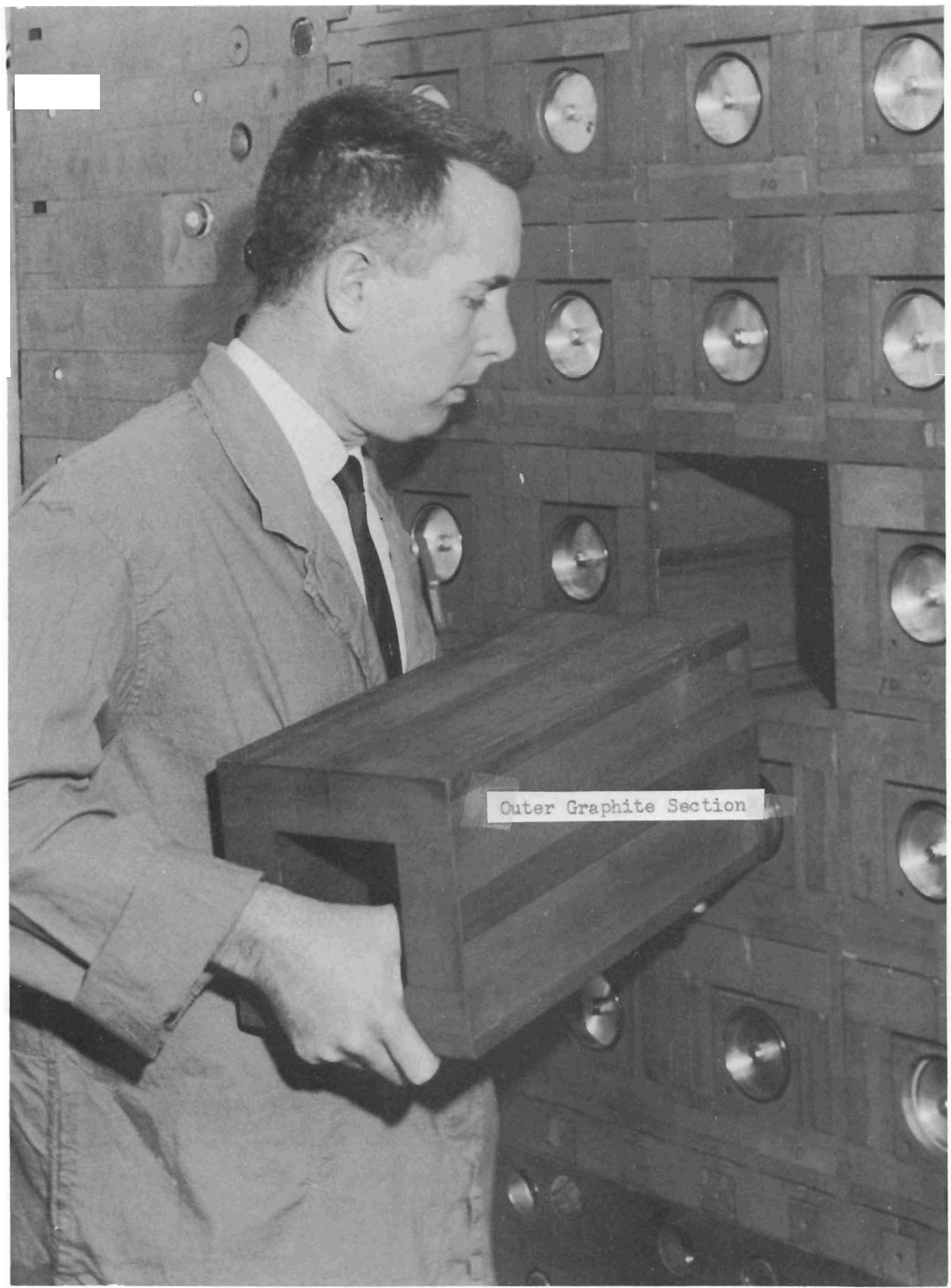

FIGURE 4. Central Test Cell Being Removed from PCTR Test Lattice 
$B N W L-1153$

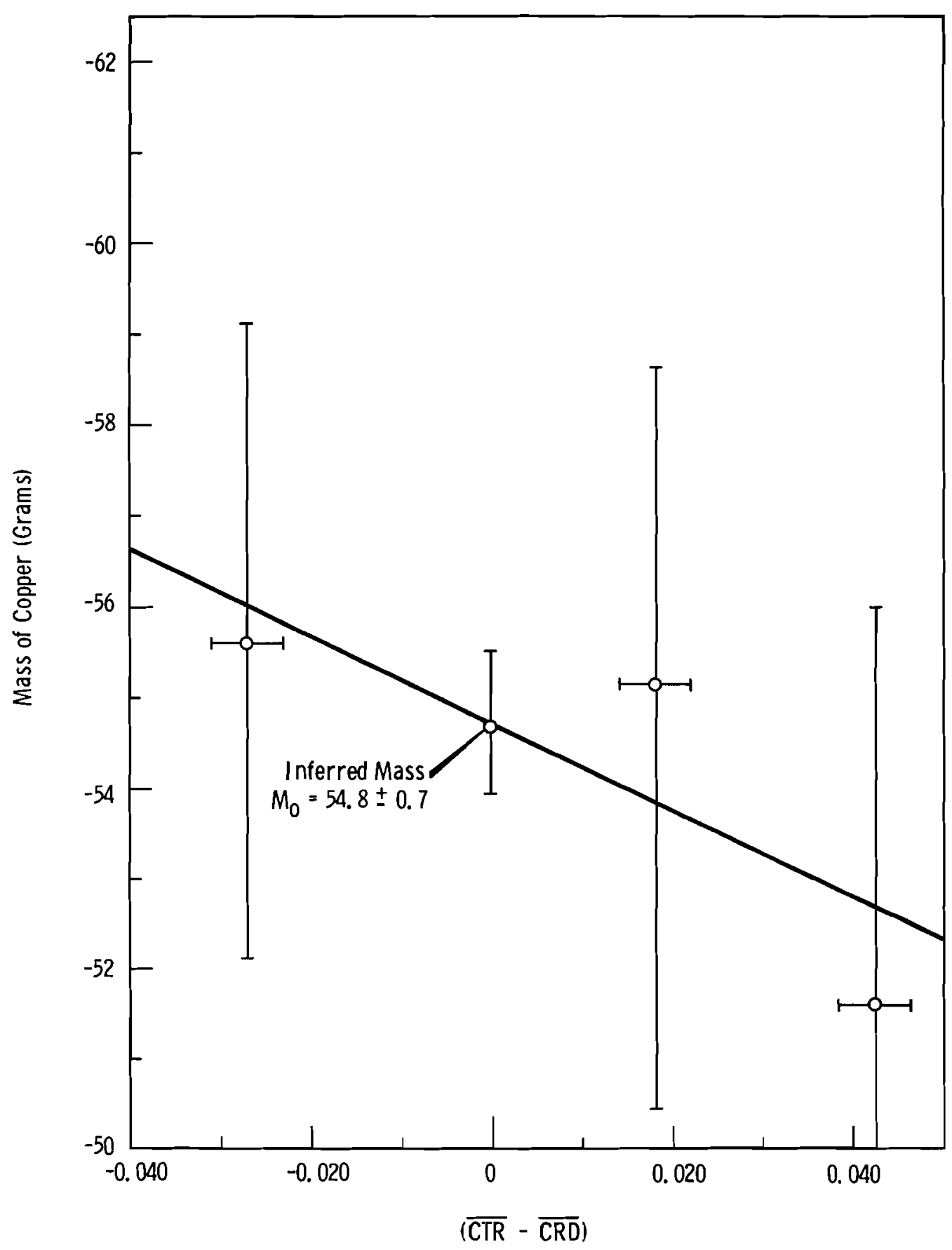

FIGURE 5. Results of Least Squares Analysis of Reactivity and Cadmium Ratio Data with Normal Coolant conditions 
$B N W L-1153$

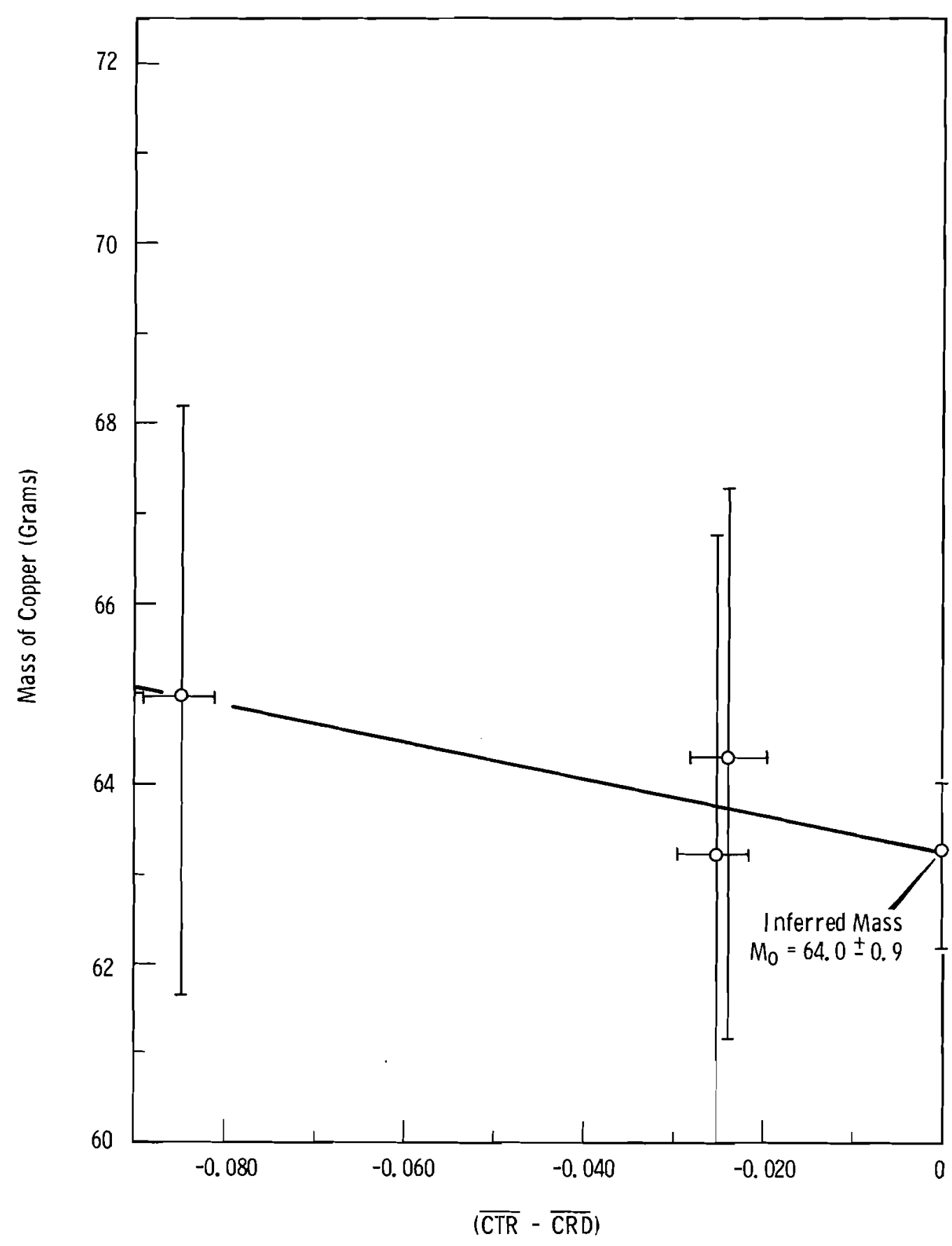

FIGURE 6. Graphic Results of Least Squares Analysis of Reactivitu Cadmium Ratio Data With Simulated Flooding conditions Around Process Tube 
$B N W L-1153$

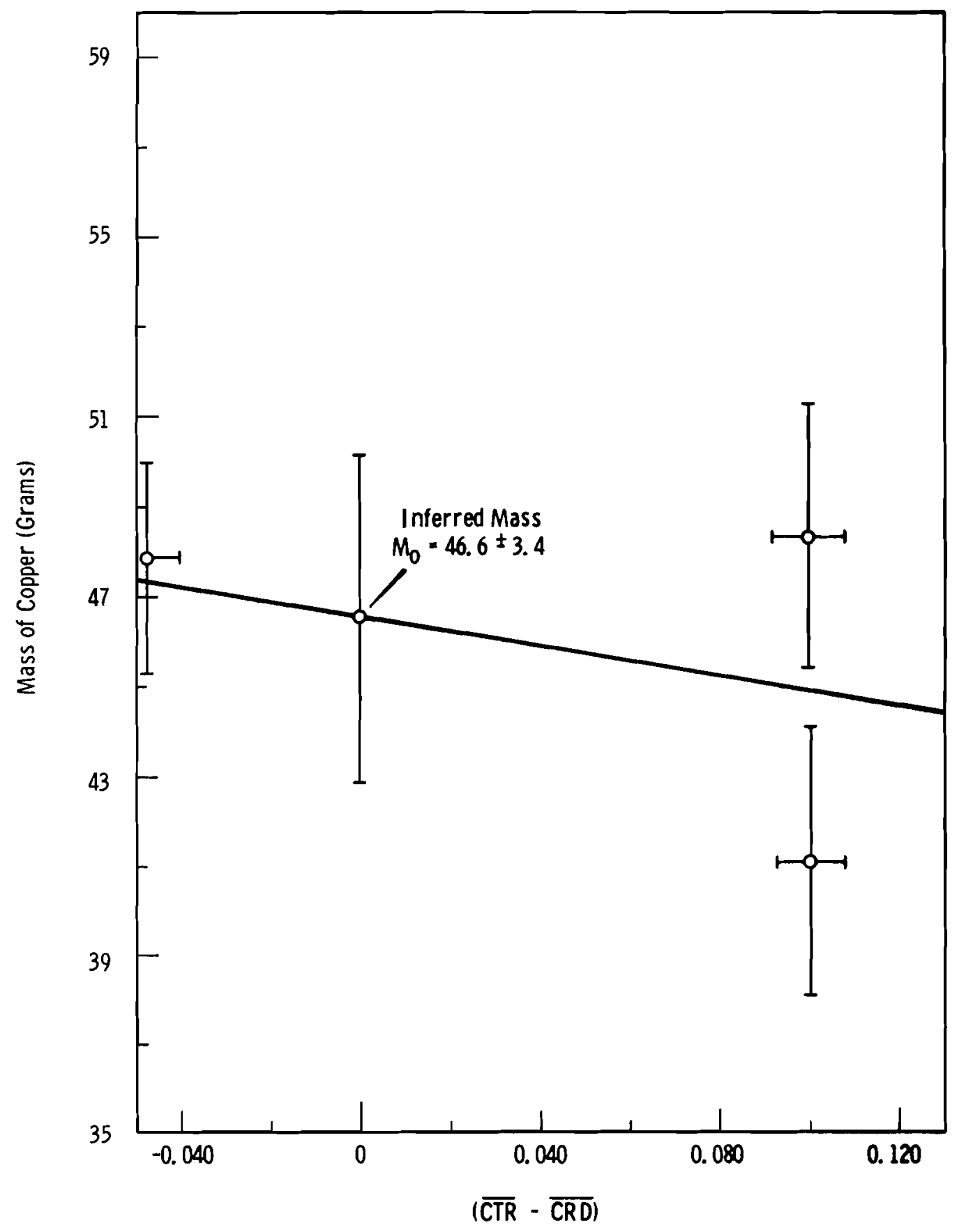

FIGURE 7. Graphic Results of Least Squares Analysis of Reactivity and Cadmium Ratio Data with Simulated Flooding Conditions Around Process Tube and in Gas vents

$$
-16-
$$


BNWL-1153

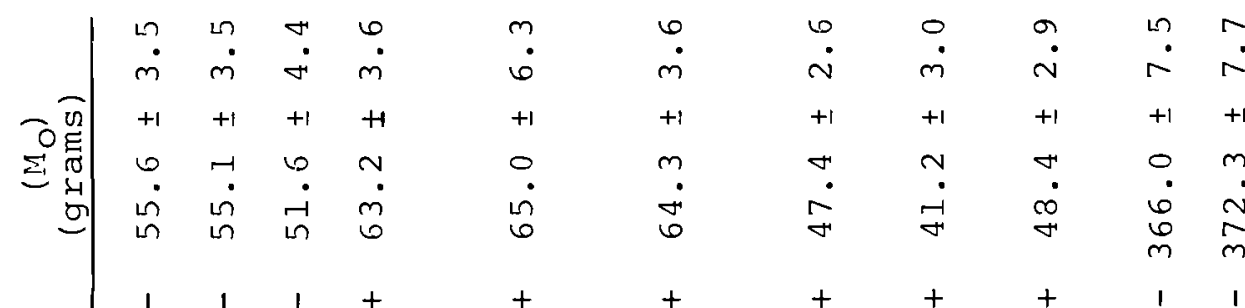
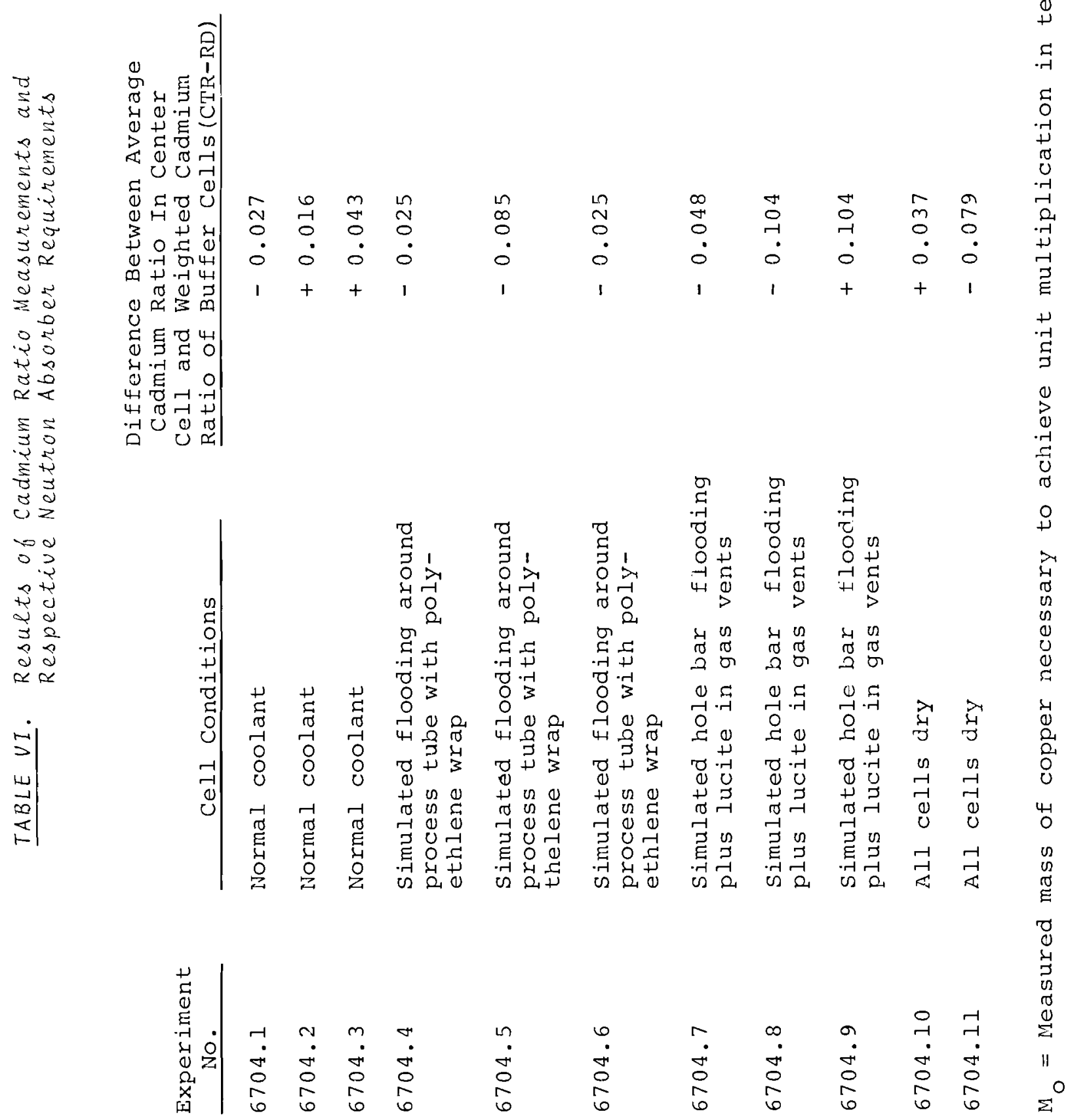
linear extrapolations of the inferred mass of copper $\left(M_{0}\right)$ to the matched cell conditions. The results are summarized in Table VII.

\section{TABLE VII. Summary of Inferred Mass of Copper and corrected $1 / v$ Mass}

\begin{tabular}{|c|c|c|}
\hline Cell Conditions & $\begin{array}{l}\text { Inferred Mass (M }) \\
\text { (grams of copper) }\end{array}$ & $\begin{array}{l}\text { Corrected } 1 / v \text { Mass } \\
\text { (gram of copper) }\end{array}$ \\
\hline Normal coolant conditions & $-54.8 \pm 0.7$ & -58.8 \\
\hline $\begin{array}{l}\text { Simulated flooding around } \\
\text { process tube }\end{array}$ & $+63.0 \pm 0.8$ & +66.3 \\
\hline $\begin{array}{l}\text { Simulated flooding around } \\
\text { process tube and in gas } \\
\text { vents }\end{array}$ & $+46.0 \pm 3.4$ & +48 \\
\hline Dry cell conditions & $-368.0 \pm 7$ & -383 \\
\hline
\end{tabular}

The results of these measurements indicate that the mass of copper ( $\mathrm{M}_{\mathrm{O}}$ ) for each condition was not found to be very sensitive to spectrum changes and therefore only a few measurements were necessary for each condition. The inferred absorber mass for the dry cell conditions was interpolated between two measurement values because the neutron spectrum in the test lattice could not be altered sufficiently to significantly change the measured mass of copper neutron absorber.

The inferred mass must be corrected to a value for a $1 / \mathrm{V}$ absorber in order to be used later to calculate $1 / \mathrm{V}$ reaction rates. These corrected values are listed in Table VI and the corrections are explained in Appendix A. 
RELATIVE REACTION RATE. AND. $K_{\infty}$ DETERMINED BY NULL REACTIVITY TECHNIQUE

\section{Foil Data}

Relative reaction rates of the test cell components are determined from foil activation measurements. The energy dependence of the reaction rates are determined from cadmium ratios.

Once the gold cadmium ratio information has indicated that the test cells have the proper energy distribution, copper foils (0.010 inch thick) and pins (0.036: inches O.D.) were strategically placed in the graphite, fuel, and coolant channels. Bare and cadmium covered foils and pins. were activated in separate irradiations and normalization between irradiations was accomplished by placing monitor foils in an external thermal $(7)$

Foil and pin locations as illustrated in Figure 8 are sufficiently provided so that radial and axial plots of the relative reaction rates can be determined throughout the center test cell. A photograph of the relative center test cell and all the associated foil holders which were used in this experiment to derive the relative reaction rates is shown in Figure 9.

Special sector and quadrant foils were made to integrate the neutron reaction rate over the area of the fuel rod and fuel tube, respectively. In order to obtain spatial detail of the reaction rate integrals, a copper sector foil and quadrant. foil from the disc foil were dissected into several annular regions after the irradiation.: These foils. were:all counted separately and yielded a histogram of specific activities relative to the monitor foil in the external thermal column.

Cadmium dishes in the separable fuel:element were: designed. so that they displaced the aluminum cladding in order to allow. the inside dimensions of the dish to be identical to the fuel 
Foils at Cell Boundary

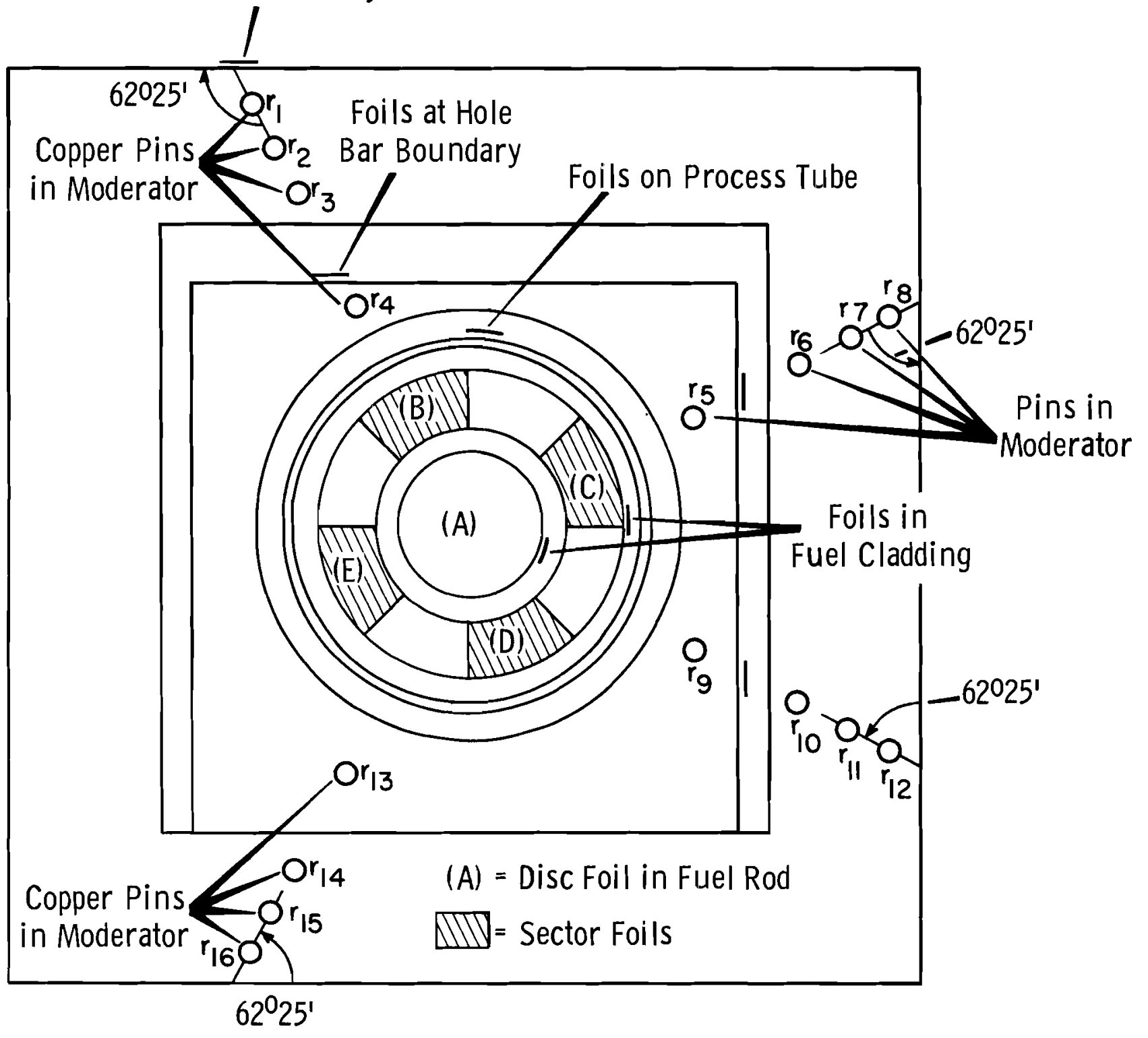

FIGURE 8. Front Face Plan of Center Test cell Showing

Foil and Pin Locations for Radial Flux Traverse 


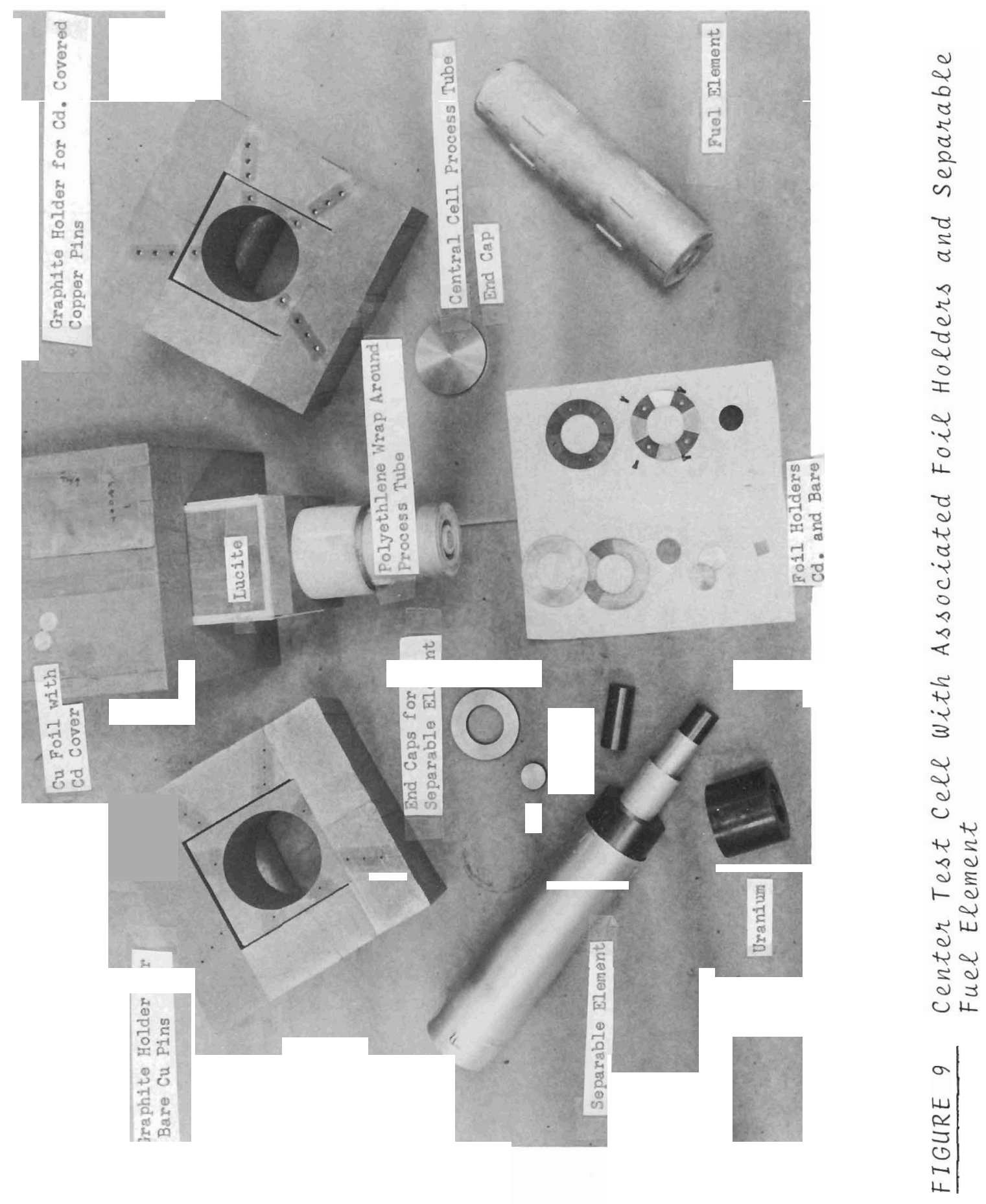


core dimensions. Foils placed inside the cadmium dish, one mil aluminum fission product catcher foils on their surfaces, were between two wafers of fuel core material, also inside the cadmium dish. Bare foils, having one mil aluminum fission product catcher foils on their surfaces, were placed in special holders machined from the core material.

The specific activation of the copper foils and pins placed in the graphite relative to the foil and pins in the thermal column are presented in Table VIII. The activities were calculated using a revised version of the computer code APDAC-I (8) which corrects the counting data for activity decay during counting, room background, foil mass variations, and residual activity. The foil activities are listed in Table VII as they were received from APDAC in order to provide a record of this unmodified foil and pin data. Further corrections must be applied for the geometrical differences if the foils and pins as well as corrections for changes in the flux due to the presence of the foil. A discussion of these corrections follow as well as a plot of the corrected activities.

The axial traverse data remained relatively constant throughout the experiment. Axial traverses were taken with 0.010 inch thick copper square foils ( 0.443 inch) by placing the foils along the fuel cladding, process tube surface and at the cell boundary. In order to give some idea of these distributions, this data has been plotted in Figure 10 for the normal coolant case. This is unmodified data, as received from the revised APDAC-I computer code calculations.

Corrections to Foil and Pin Data (See Appendix A)

Several corrections must be applied to the foil and pin data after the APDAC calculated corrections. A geometry correction for the pin data is applied by multiplying the activities of the pins by the ratio of the activities of a 0.010 inch thick copper 
BNWL- 1153

\begin{tabular}{|c|c|c|c|c|c|c|c|c|c|c|c|}
\hline 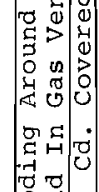 & 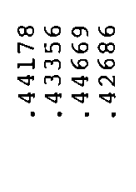 & 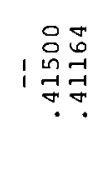 & 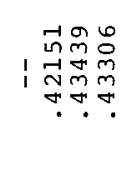 & 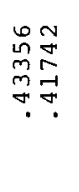 & 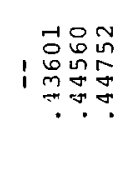 & 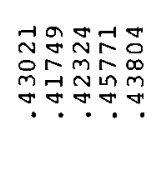 & \begin{tabular}{l}
8 \\
$\stackrel{0}{0}$ \\
in \\
\multirow{r}{*}{.}
\end{tabular} & $\begin{array}{lllll}1 & 1 & 1 & 1 & 1\end{array}$ & 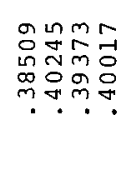 & 11 & \begin{tabular}{l}
$\infty$ \\
\multirow{2}{*}{} \\
o \\
\multirow{7}{*}{}
\end{tabular} \\
\hline 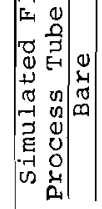 & 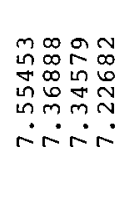 & 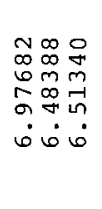 & 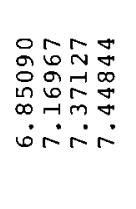 & 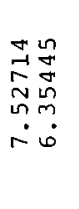 & 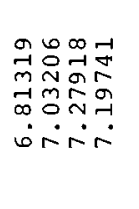 & 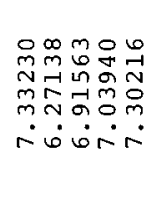 & $\begin{array}{l}N \\
o \\
0 \\
-1 \\
\vdots \\
\therefore\end{array}$ & 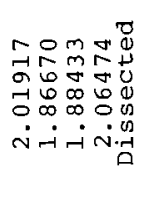 & 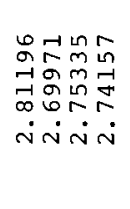 & $\begin{array}{l}\infty \\
\stackrel{\infty}{N} \\
1 \\
1 \\
i \\
\dot{\pi}\end{array}$ & 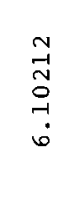 \\
\hline 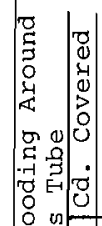 & 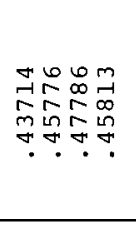 & 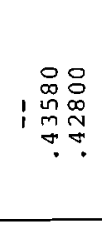 & 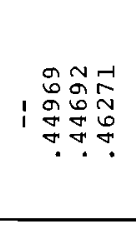 & 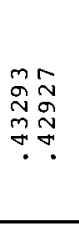 & 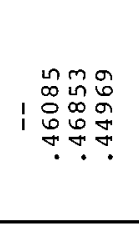 & 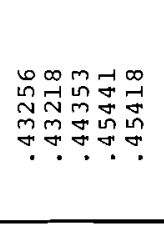 & $\begin{array}{l}m \\
\stackrel{m}{n} \\
m \\
\stackrel{m}{*}\end{array}$ & 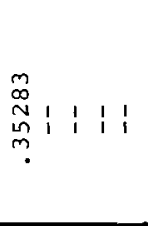 & 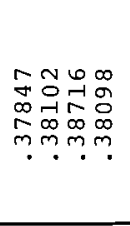 & 11 & $\begin{array}{l}8 \\
\stackrel{8}{\circ} \\
\stackrel{0}{7}\end{array}$ \\
\hline 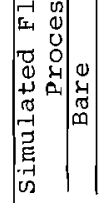 & 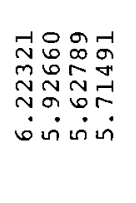 & 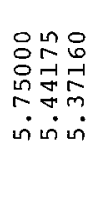 & 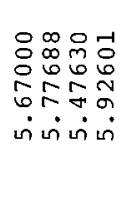 & 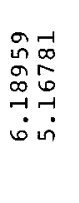 & 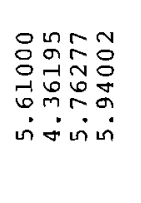 & 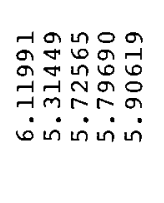 & $\begin{array}{l}-1 \\
5 \\
6 \\
-1 \\
\dot{0}\end{array}$ & 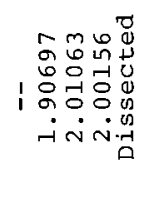 & 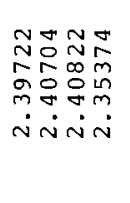 & 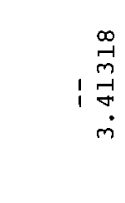 & 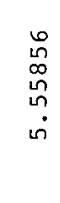 \\
\hline 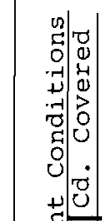 & 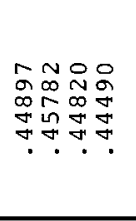 & 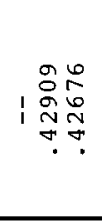 & 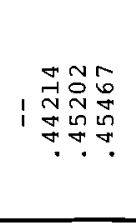 & 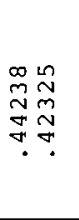 & 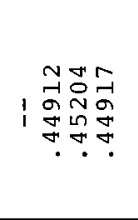 & 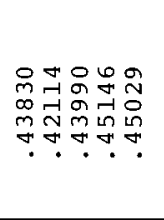 & $\begin{array}{l}0 \\
0 \\
6 \\
m \\
\vdots \\
0\end{array}$ & 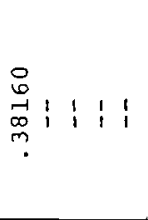 & 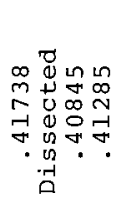 & in & $\begin{array}{l}\circ \\
\text { ํㅜ } \\
\text { o } \\
\text { ? }\end{array}$ \\
\hline 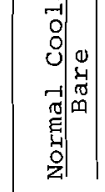 & 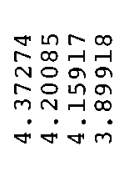 & 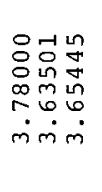 & 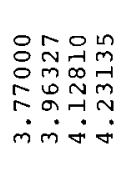 & 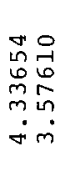 & 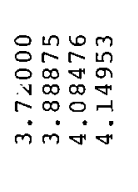 & 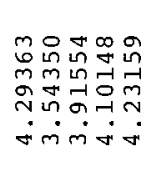 & $\begin{array}{l}-1 \\
\circ \\
\circ \\
o \\
\sim \\
\dot{\sigma}\end{array}$ & 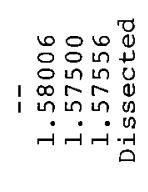 & 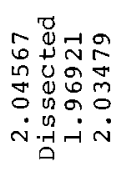 & $\begin{array}{l}\vec{J} \\
i \\
i \\
\dot{N}\end{array}$ & 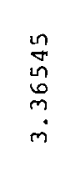 \\
\hline 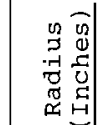 & 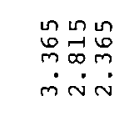 & $\begin{array}{l}\text { ma: } \\
\text { r } \\
\text {-i }\end{array}$ & 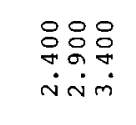 & 욤 & 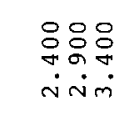 & 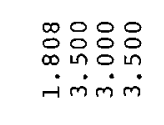 & & & & $\begin{array}{l}\vec{n}-1 \\
m=-1 \\
\ddot{0}-1\end{array}$ & $\begin{array}{l}\stackrel{0}{m} \\
m \\
m \\
-i\end{array}$ \\
\hline 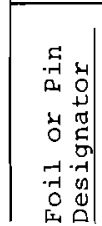 & 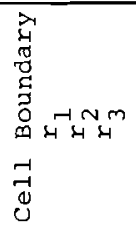 & 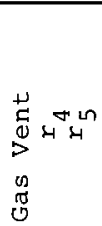 & 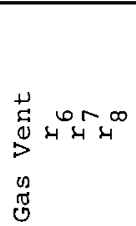 & $\begin{array}{l}x_{1} \\
0 \\
0 \\
0 \\
5 \\
0 \\
0 \\
0.4 \\
7 \\
7 \\
0 \\
0\end{array}$ & $\begin{array}{l}+ \\
0 \\
0\end{array}$ & 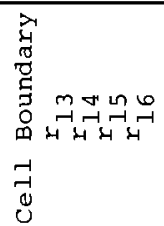 & 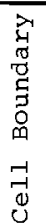 & 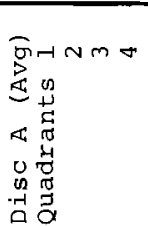 & 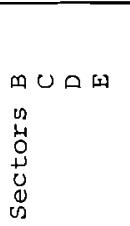 & 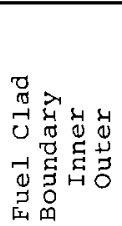 & 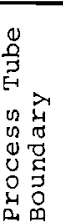 \\
\hline
\end{tabular}




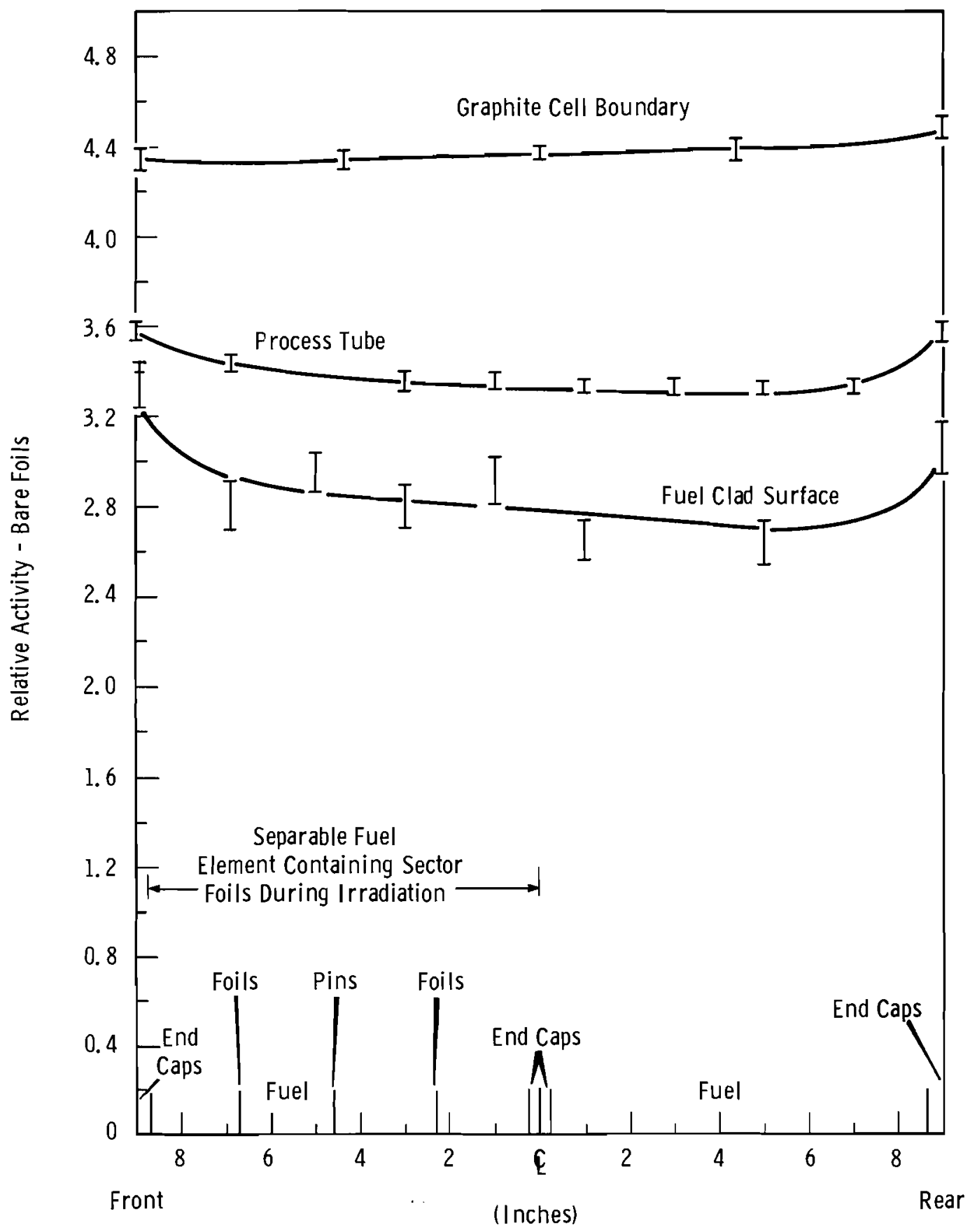

FIGURE 10. Axial Traverse Data of Bare Foils on outer cell with Normal Coolant Conditions 
foil and pin irradiated simultaneously in the thermal column during each irradiation.

It is also necessary to correct for the change in the flux in any region due to the foil's presence in the same region. This correction follows a method derived by F. E. Dunn (KAPL) (9) and uses the equation shown below:

$$
\frac{\mathrm{A}_{\text {foil }}{ }^{-\mathrm{A}_{O}}}{\mathrm{~A}_{\text {foil }}}=t\left(\Sigma_{\text {medium }}{ }^{\left.-\Sigma_{\text {foil }}\right)} \ln \mathrm{L} / \mathrm{t}\right.
$$

where $\mathrm{A}_{\text {foil }}=$ Activation of foil as measured in medium

$\mathrm{A}_{\mathrm{O}} \quad$ Activation that would occur if the flux in the foil were the same as the flux in the medium

$t \quad=$ Thickness of foil (cm.)

$\Sigma_{\text {medium }}$ Macroscopic absorption cross section of medium

$\Sigma_{\text {foil }}=$ Macroscopic absorption cross section of foil

$\mathrm{L} \quad=$ Diameter of foil (cm.)

The measured spatial distribution of the relative reaction rates in copper-63, $\mathrm{SA}^{63}$, must also be corrected for non-1/V absorption reactions. These non-1/v corrections were inferred from copper-63 cadmium ratio measurements and resonance integral data ${ }^{(6)}$.

$$
\mathrm{SA}_{1 / \mathrm{V}}^{63}(\mathrm{R})=\mathrm{SA}_{\text {total }}^{63}(\mathrm{R})-\mathrm{SA}_{\text {epi-cd. }}^{63} \cdot \frac{\mathrm{RI} \text { ex. }}{\mathrm{RI} \text { epi-cd. }}
$$

$\begin{aligned} \text { where } \mathrm{RI}_{\text {ex }} \quad= & \text { effective excess resonance integral for } \\ & \text { copper }-63 \text { in a } 0.010 \text { inch thick foil, }\end{aligned}$ 1.631 barns

$\mathrm{RI}_{\text {epi-cd }}=$ effective total epi-cd. resonance integral for copper-63 in. a 0.010 inch thick foil, 3.420 barns 
Comparison of lleasured Foil Activities With THERMOS Calculations

The THERMOS $(10)$ code was used to derive the radial flux patterns for each type cell condition under consideration in this experiment. The theoretical patterns were then plotted with the radial patterns derived from the experimental irradiations and with each case normalized to unity at the inner fuel rod. These graphs are presented in Figures 11,12 and 13 .

Neutron Cross Sections

Thermal neutron spectrum averaged microscopic cross section values, calculated by transport theory, were obtained from the computer code THERMOS(10). Single cell calculations were made for each type of cell, both wet and dry, with and without copper absorber at the cell boundary, in a cylindricized geometry, and with a reflecting boundary condition at the other cell surface.

In general the cross sections calculated by THERMOS are defined as :

$$
\Lambda(r)=\frac{\int_{o}^{E_{e c}} \sigma(E) \phi(E, r) d E}{\int_{0}^{E_{e c}} \sqrt{E_{O} / E} \phi(E, r) d E}
$$

where, $E_{\text {ec }} \quad=$ upper limit of the thermal neutron spectrum, taken as $0.683 \mathrm{ev}$.

$\mathrm{E}_{\mathrm{O}} \quad=0.0253 \mathrm{ev}$

$\phi(E, r)=$ space-energy distribution of neutrons 


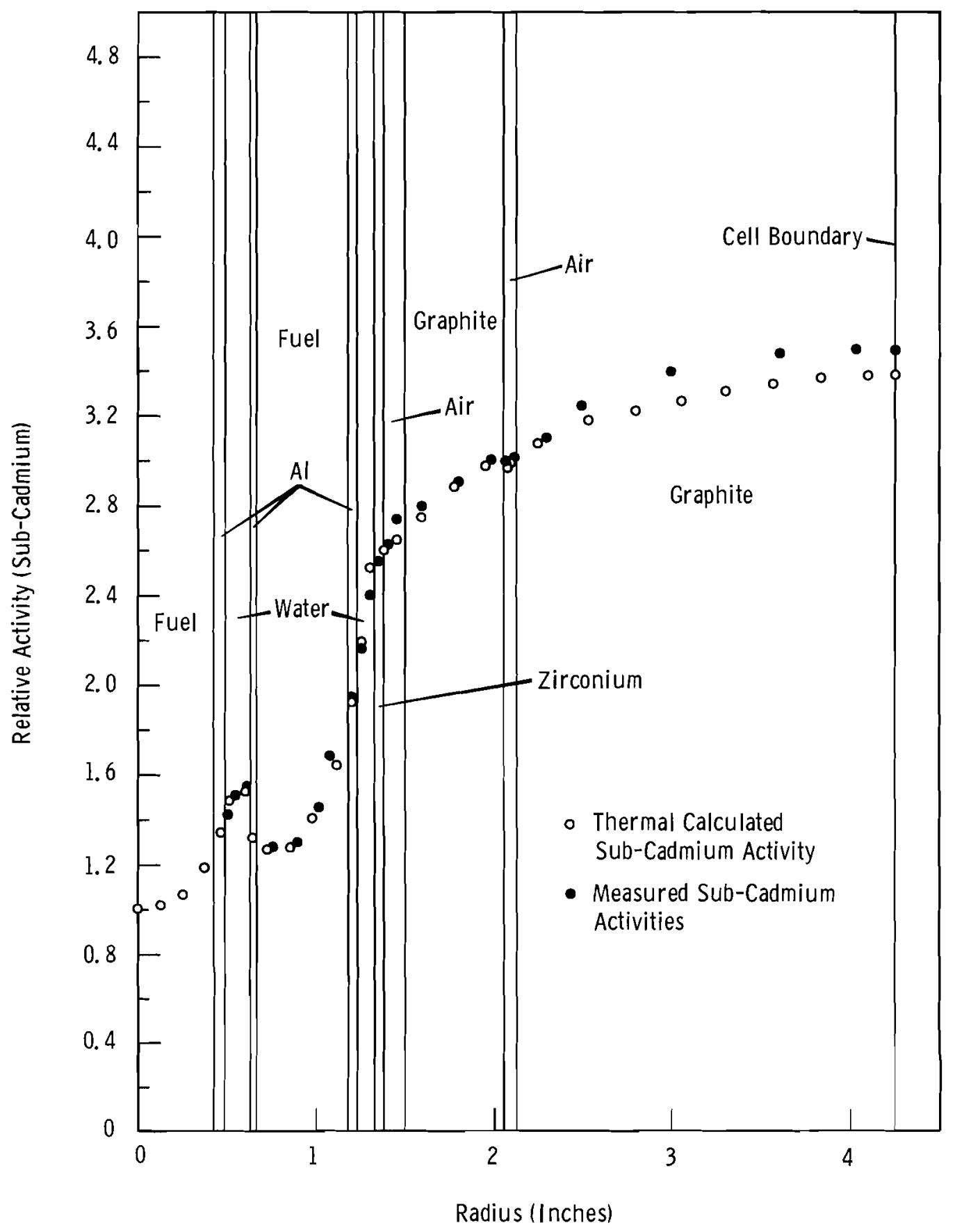

FIGURE 11. Radial Flux Plots Derived bu Experiment and THERMOS Calculations INormal Coolant Conditions! 
$B N W L-1153$

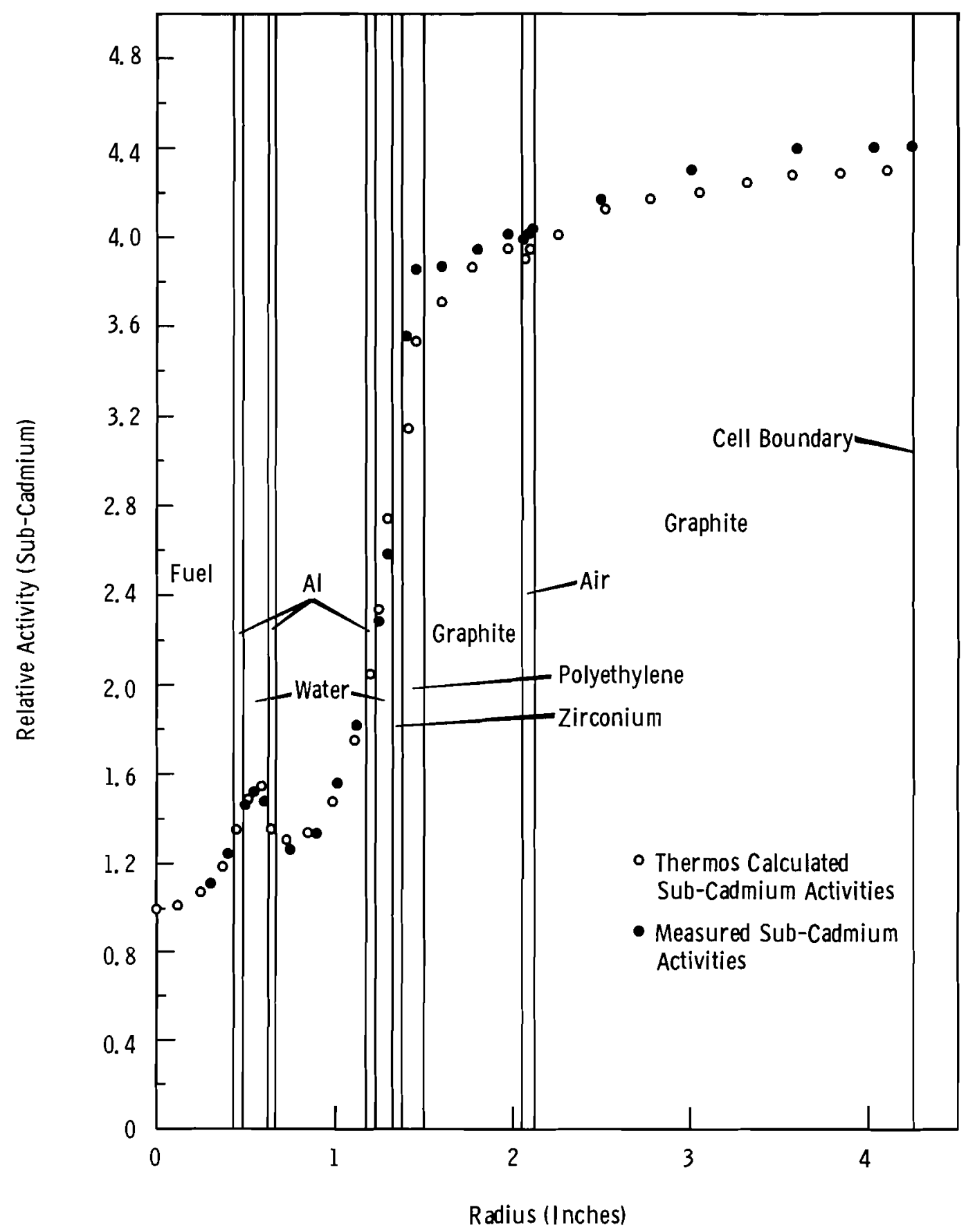

FIGURE 12. Radial Flux Plots Derived by Experiment and THERMOS Calculations ( Simulated Process Channel Floodingl 
$B N W L-1153$

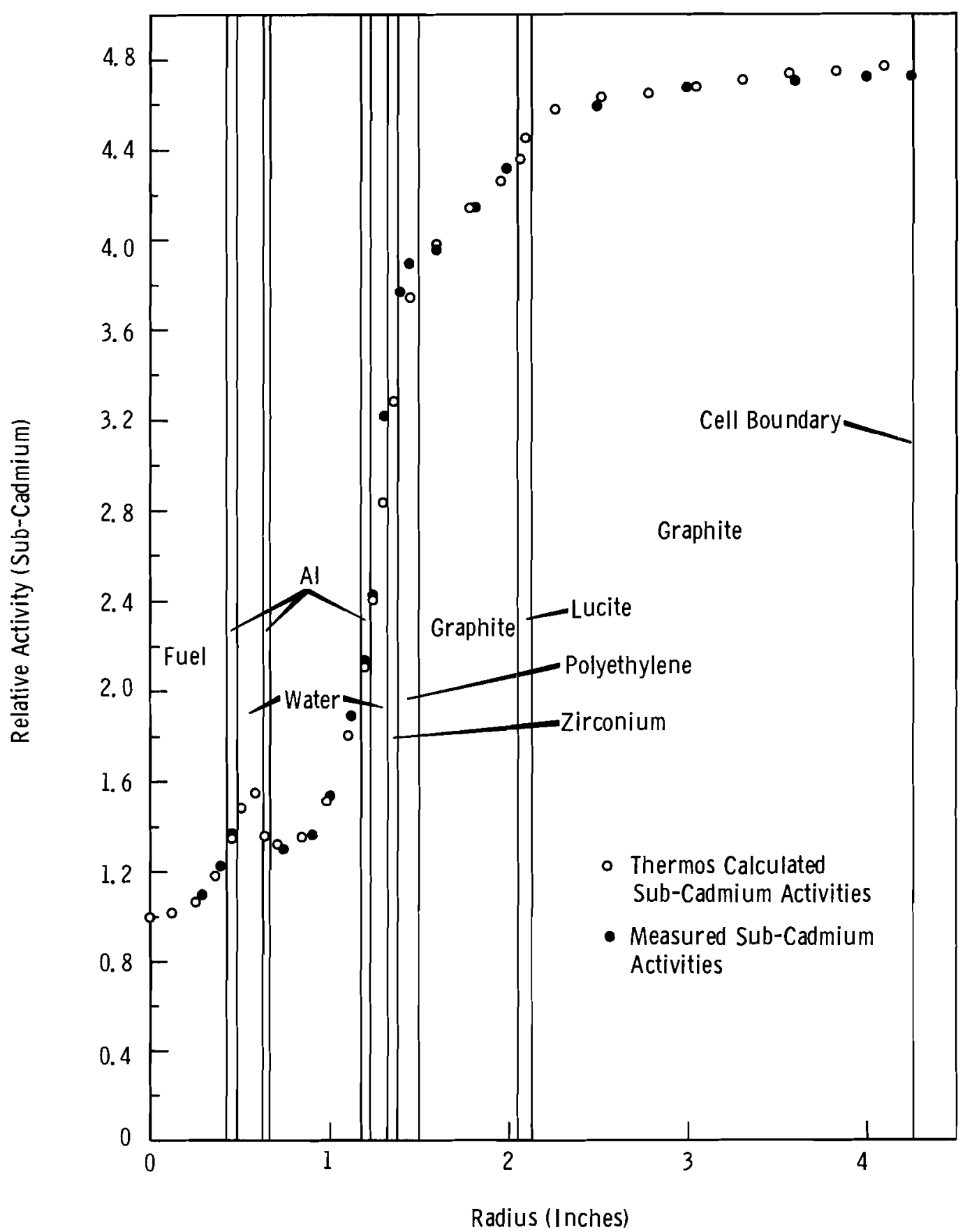

FIGURE 13. Radial Flux Plots Derived bu Experiment and THERMOS calculations ( Simulated Process Channel and Gas Vent Floodingl 
Region averaged THERMOS cross sections calculated using the previously described technique are presented in Tables $I X, X$ and $X I$ for the basic cell conditions measured in this experiment.

As defined in the previous equation, the values will be $2200 \mathrm{~m} / \mathrm{sec}$ values unless the cross section is non-l/v for $O \leq E \leq 0.683 \mathrm{ev}$.

\section{l/v Utilization}

The $1 / v$ utilization of a cell component is defined as the ratio of the $1 / \mathrm{V}$ neutron energy absorption rate in that component, to the sum of the $1 / v$ absorption rates in all cell components. The experimental values of this parameter are derived from the calculated cross section data and the:experimentally measured $1 / \mathrm{V}$ neutron reaction rate in Copper-63. At space point $r$ the $1 / \mathrm{v}$ absorption rate in Copper-63 is given by:

$$
\overline{S A}^{63}(r)=C \frac{N_{O}}{A^{63}} \quad \begin{gathered}
\Lambda 63 \\
(r)
\end{gathered} \int_{0}^{E_{O}} \sqrt{E_{O} / E} \phi(E, r) d E,
$$

where $C$ is a space independent normalizing constant.

A similar value of $\overline{S A} x$ for the material, $x$, in any given region, may be obtained from the simple ratio:

$$
\overline{S A}_{(r)}=\frac{\hat{\sigma}_{\mathrm{X}}(r) A^{63}}{\hat{\sigma}_{63}(r) A^{\mathrm{x}}} \quad \overline{S A}^{63}(r)
$$

where $A$ is the atomic weight.

The total $1 / \mathrm{V}$ absorption rate in material $\mathrm{x}$, (Abs) $\mathrm{x}$, may be obtained for a region by the volume weighted average of $\overline{\mathrm{SA}}^{\mathrm{X}}(\mathrm{r})$ :

$$
(\text { Abs })^{x}=M^{x} \frac{\int S A^{x}(r) d V}{\text { All of region } x}
$$


BNWL-1153

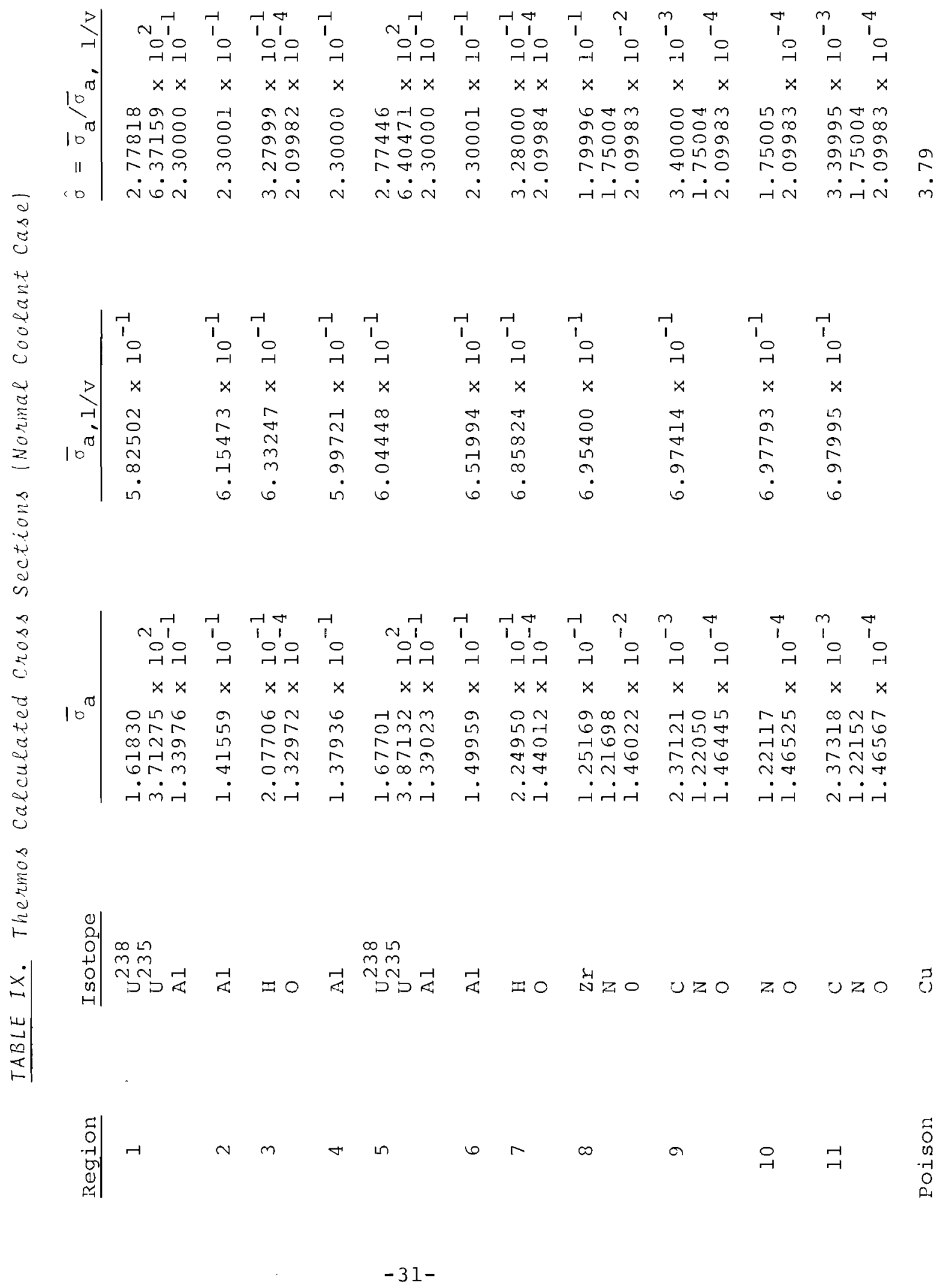


BNWL-1153

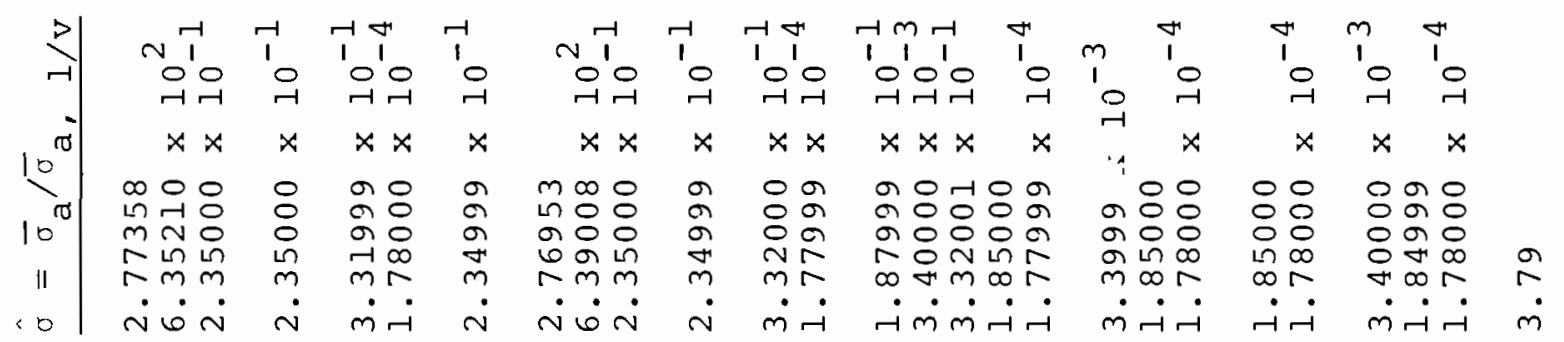

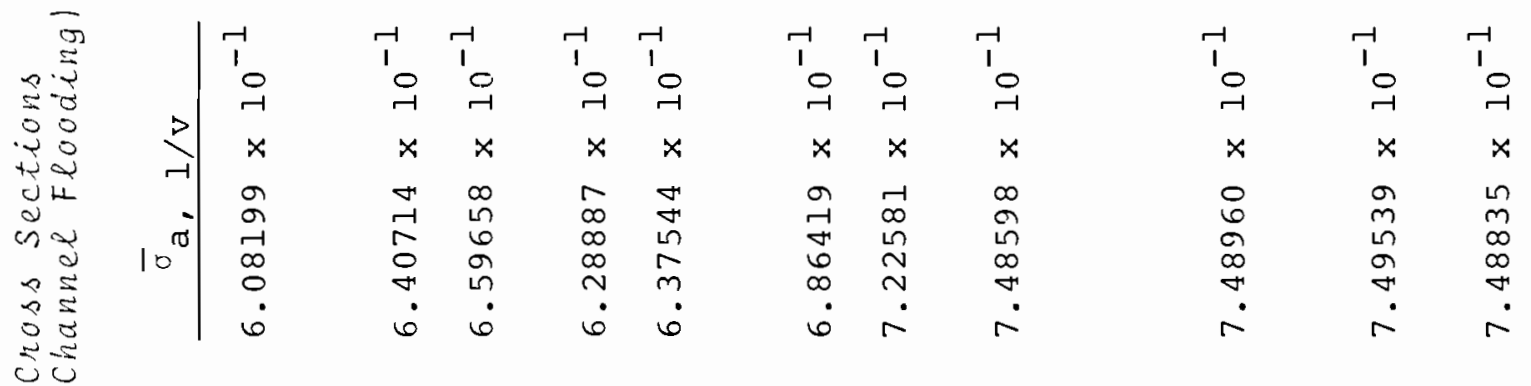

$\tau$

2

से

0

उस

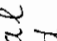

$\begin{array}{ll}0 & 0 \\ 0 & 0\end{array}$

$0 \stackrel{0}{0}$

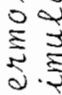

3
2

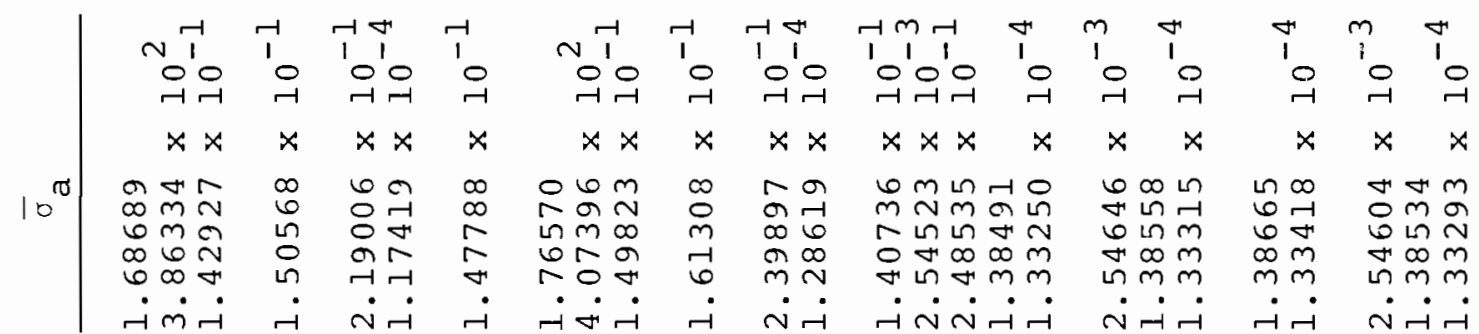

$x$
4
$\frac{1}{0}$
$\frac{1}{5}$

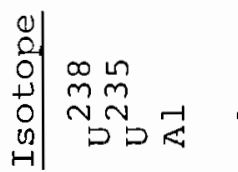

$-\quad-\stackrel{\infty}{\sim} \stackrel{n}{\sim}$

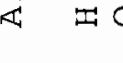

更出

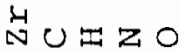

$0 \geq 0$

zo

Ura 3

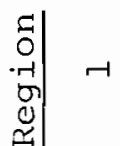

$\sim$

$m$

$\nabla$

เก

$6 r$

$\infty$

$\sigma$

$\stackrel{\circ}{ન}$ 
BNWL- 1153

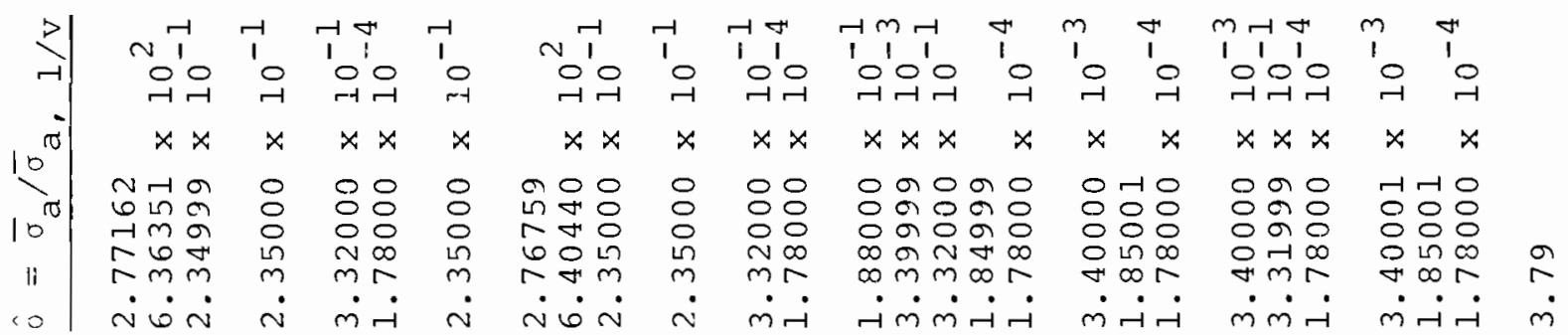

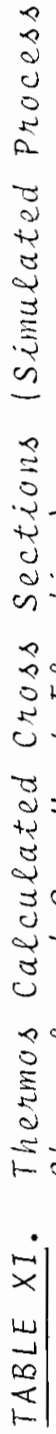

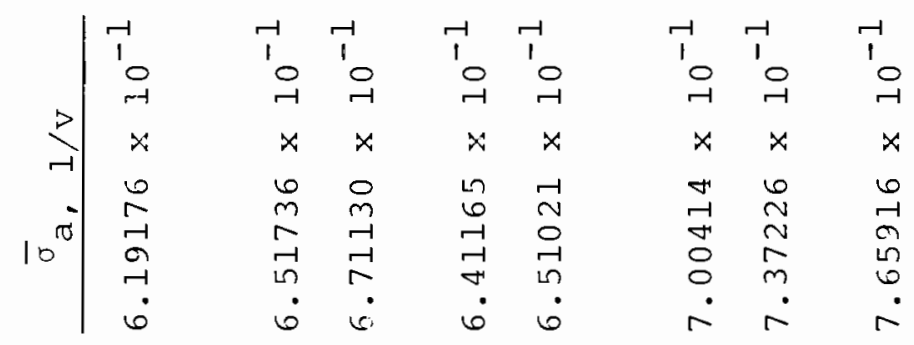

\begin{tabular}{|c|c|}
\hline 강 & 감 \\
\hline$x$ & $x$ \\
\hline$\stackrel{\sim}{\sim}$ & $\overrightarrow{+}$ \\
\hline 6 & in \\
\hline o & $m$ \\
\hline$\therefore$ & $\therefore$ \\
\hline
\end{tabular}

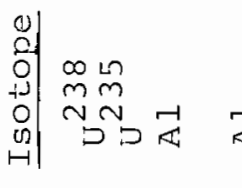

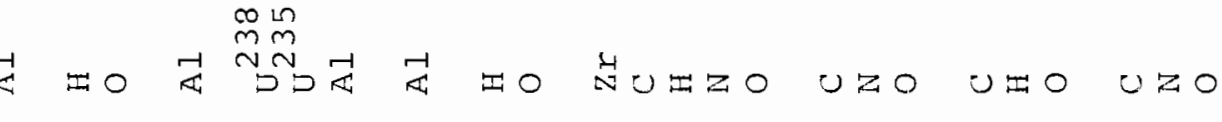

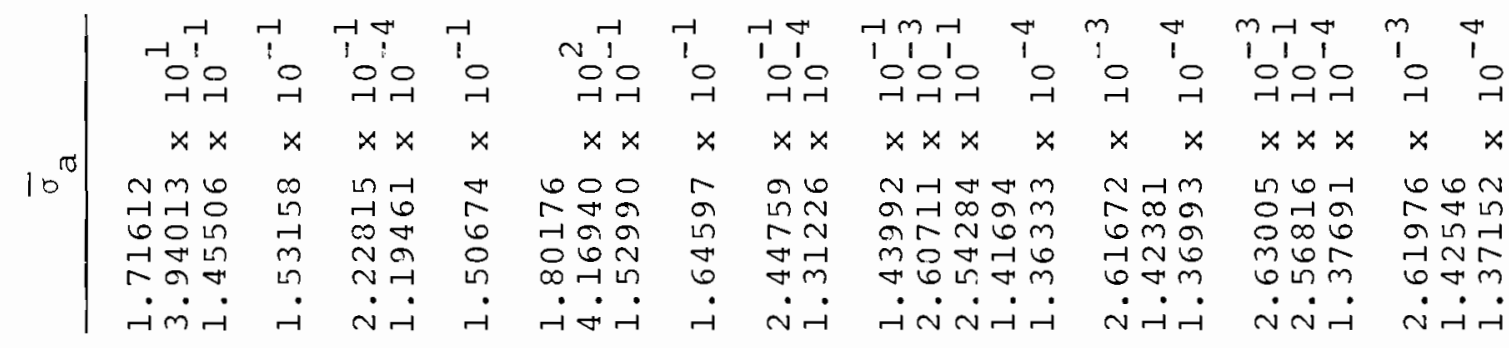

$\infty$

至

$\stackrel{5}{5}$

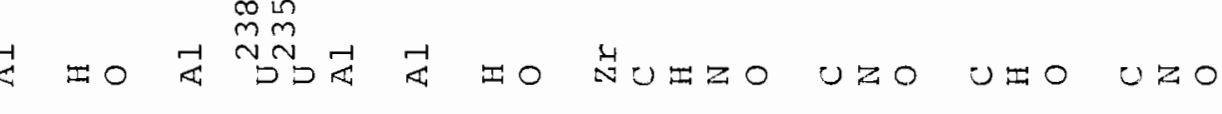

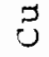

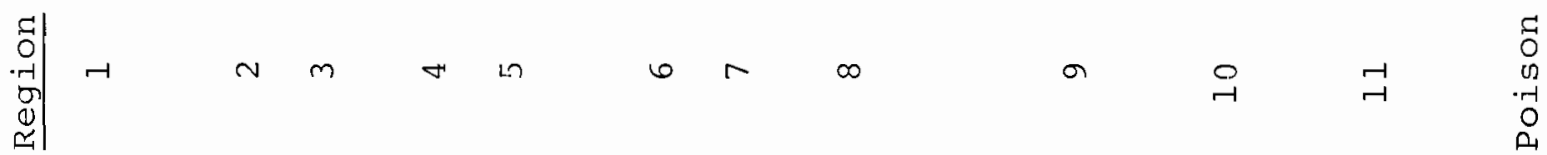


Finally, the the $1 / \mathrm{v}$ utilization of material $\mathrm{x}$ is

$$
f^{x}=(A b s)^{x} / \sum_{i}(A b s) i
$$

Absorption rates for all cell components and $1 / \mathrm{v}$ utilizations of these components are presented in Tables XII, XIII and XIV.

Determination of $\mathrm{k}_{\infty}$

In a simple uranium fueled system, the equations for calculating $k_{\infty}$ can be derived from the four factor formula(1l):

$$
\mathrm{k}_{\infty}=n \in \mathrm{pf}
$$

It is assumed that the addition of copper to the boundary of the supercell will change only the thermal utilization. Since the multiplication factor, $\left(k_{\infty}{ }^{\prime}\right)$ of the supercell with the correct mass of copper (Mo) is unity;

$$
\mathrm{k}_{\infty}^{\prime}=n \in \mathrm{pf} f^{\prime}=1
$$

Therefore, $k_{\infty}$ has been derived $(1,2)$ as the ratio of the unpoisoned to poison thermal utilizations of the supercell, $\mathrm{k}_{\infty}=\frac{\mathrm{f}}{\mathrm{f}}$, where

$\mathrm{f}=$ the $1 / \mathrm{V}$ utilization of the unpoisoned supercell;

$f^{\prime}=$ the $1 / v$ utilization of the poisoned supercell.

The derivation of the $f_{1 / v}$ in the equation above is based on the assumption that the absorption rates in all the cell components, except for the resonance absorption in ${ }^{238} \mathrm{U}$, can be calculated using the flux measured by a detector whose absorption cross section varies as $1 / \sqrt{\mathrm{E}}$ multiplied by the effective $2200 \mathrm{~m} / \mathrm{sec}$ cross section calculated by THERMOS. The material used as the absorber in the determination of $\mathrm{k}_{\infty} \mathrm{l} / \mathrm{v}$ must also have an effective cross section that varies as $1 / \sqrt{\mathrm{E}}$. The use of the four factor formula in the derivation of $\mathrm{k}_{\infty} \mathrm{l} / \mathrm{v}$ implies that:

$$
\mathrm{k}_{\infty} 1 / \mathrm{v}=n_{1 / v} \varepsilon \mathrm{p}_{\text {non } 1 / v} \mathrm{f}_{1 / \mathrm{v}}
$$




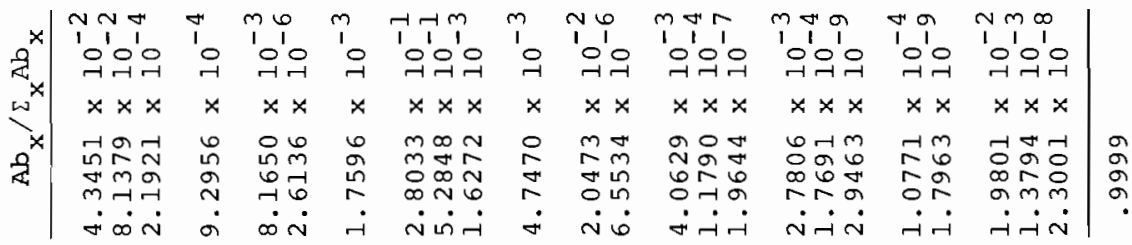

BNWL- 1153

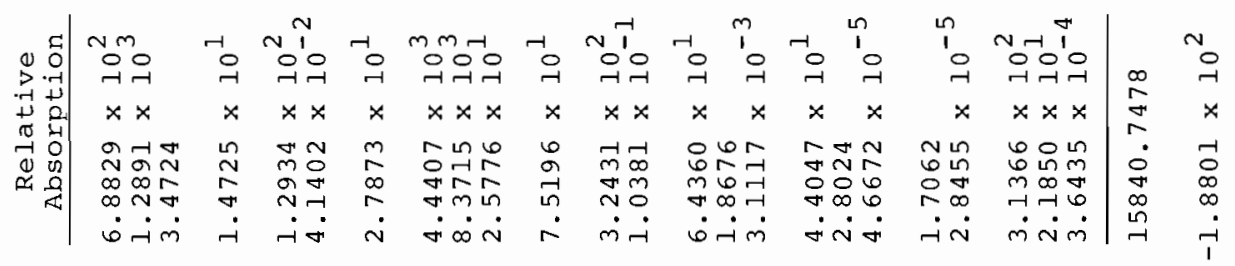

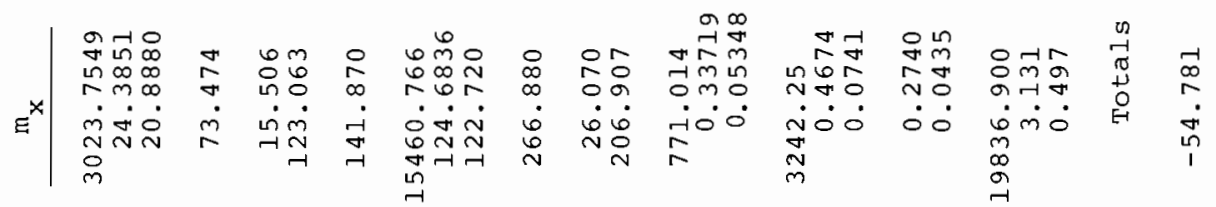

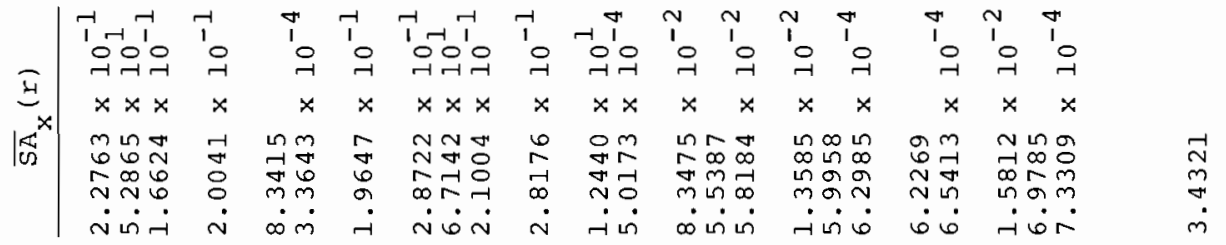

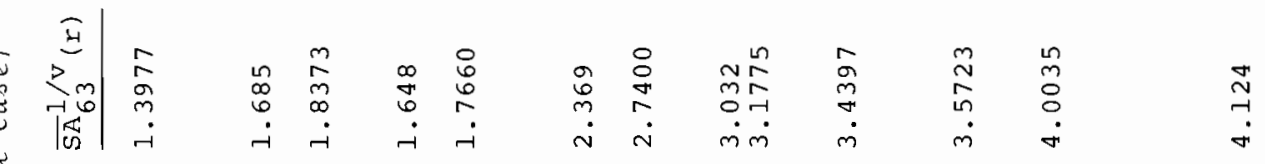

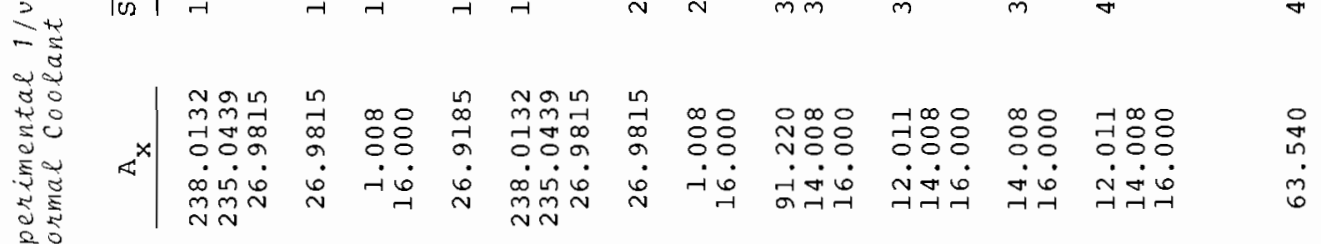

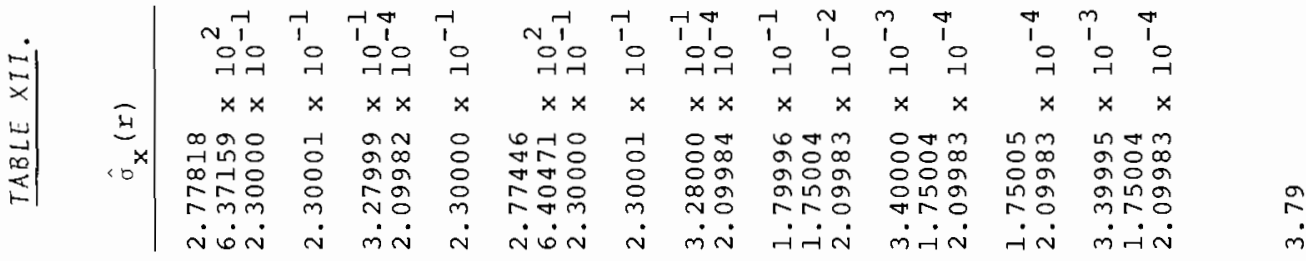

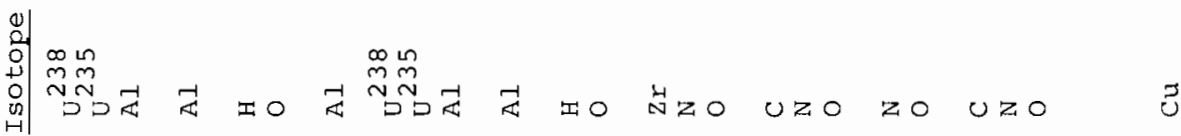

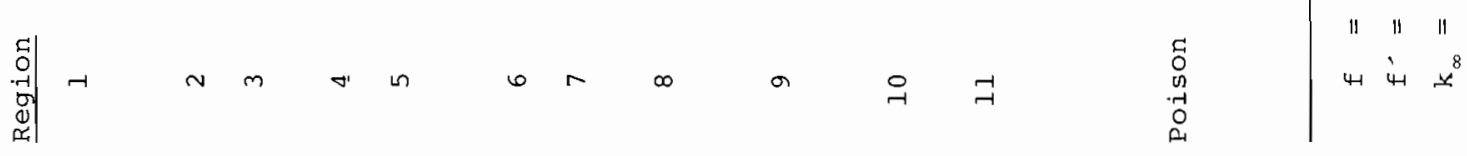


BNWL-1153
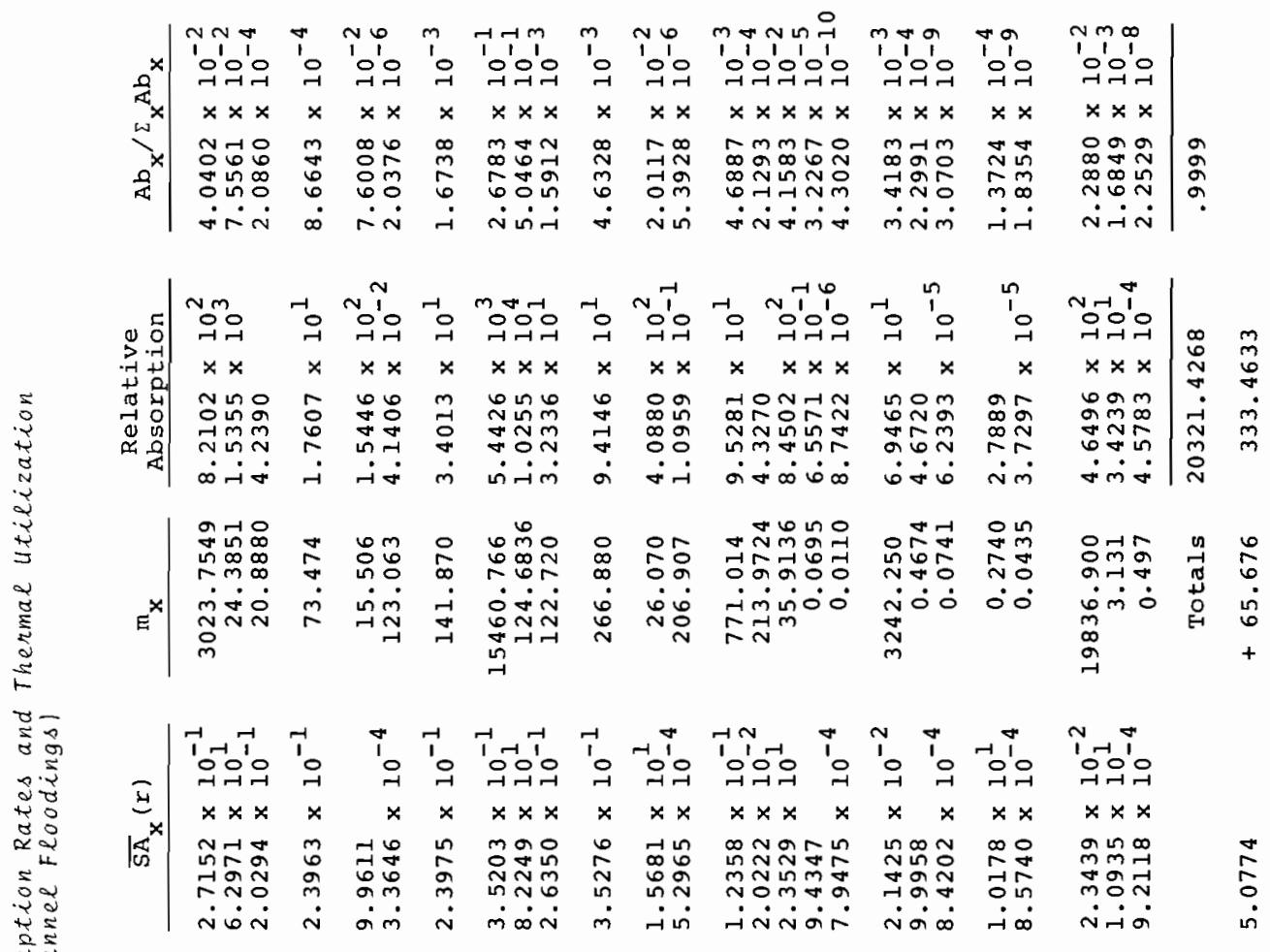

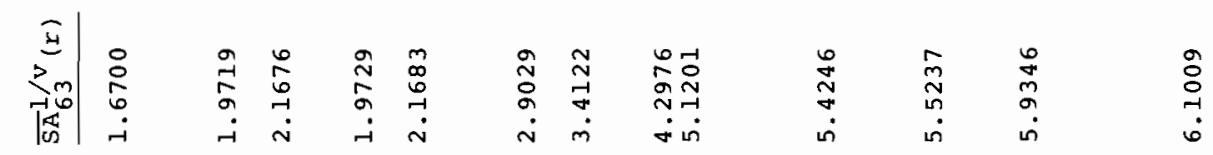

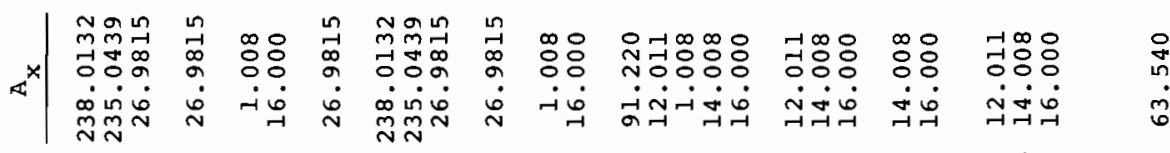

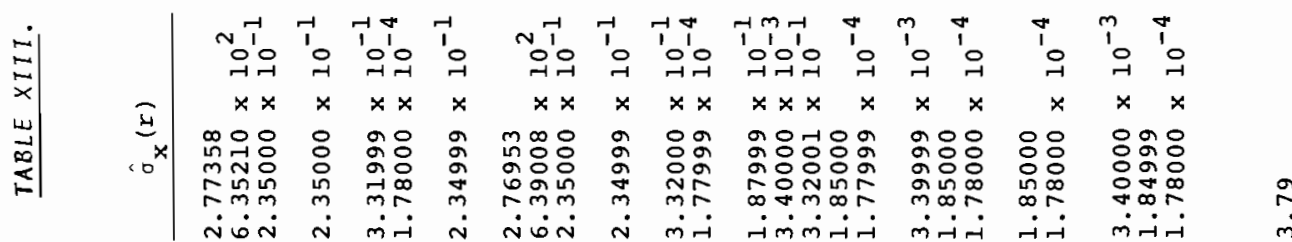

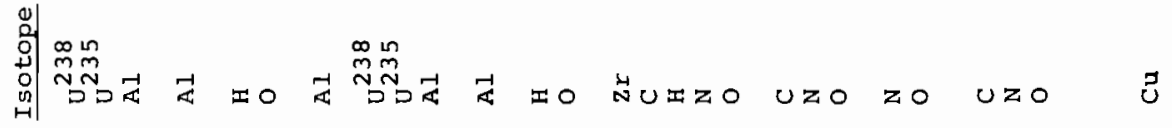

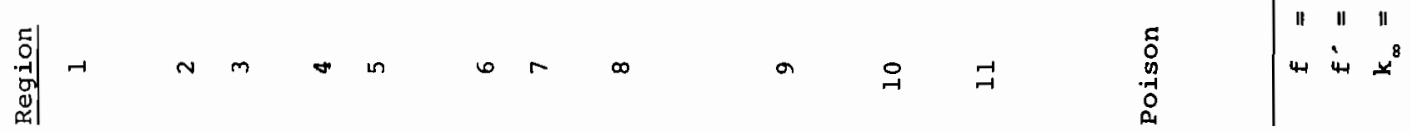


BNWL -1153
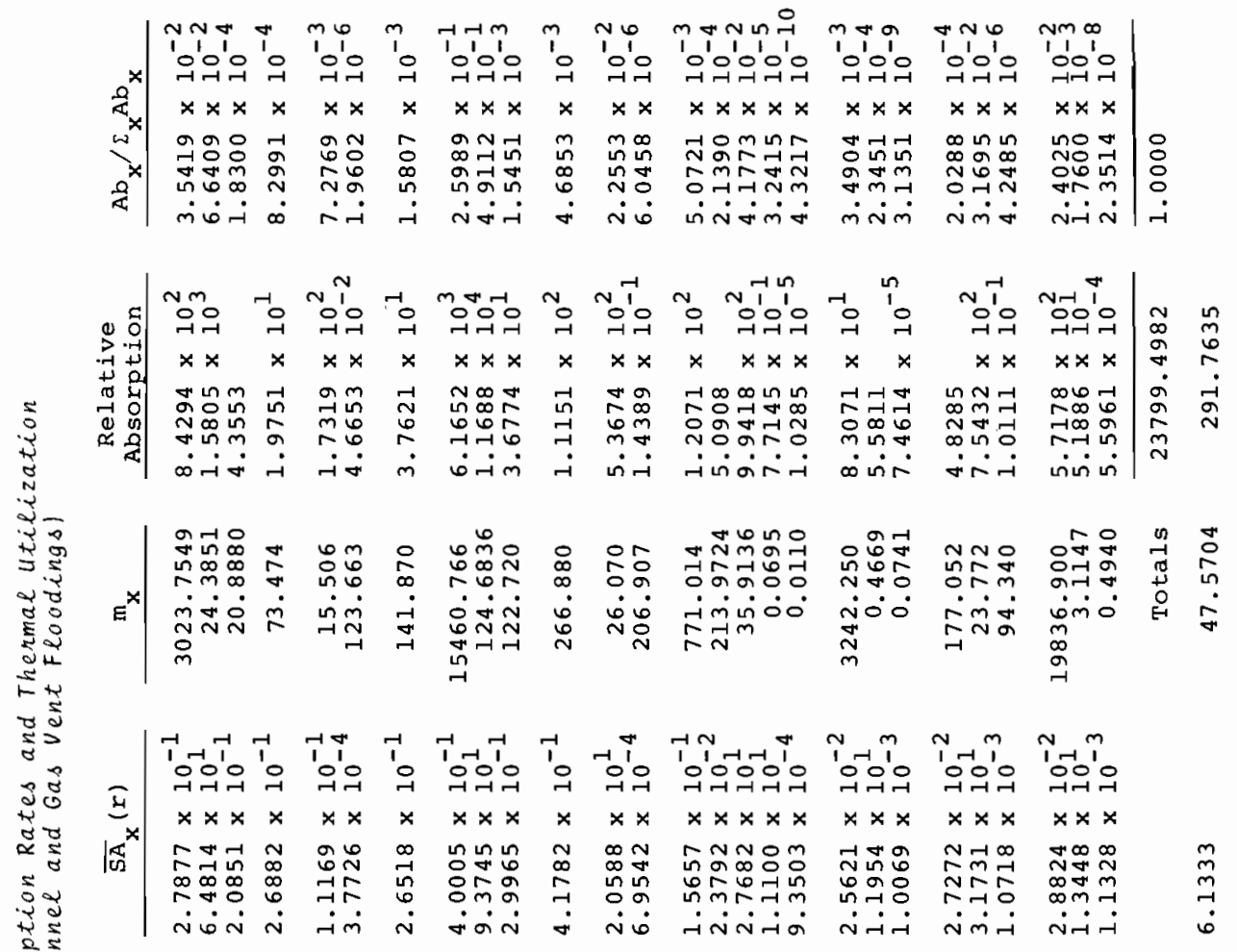

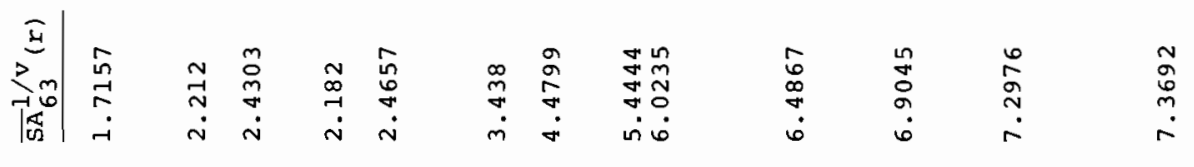

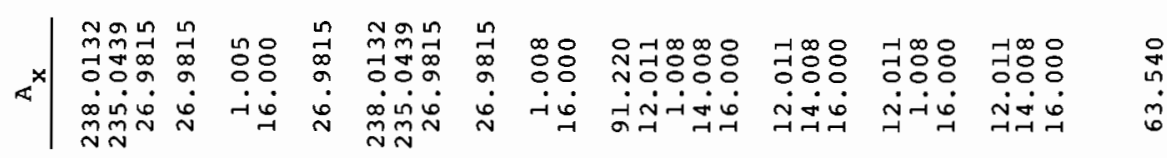

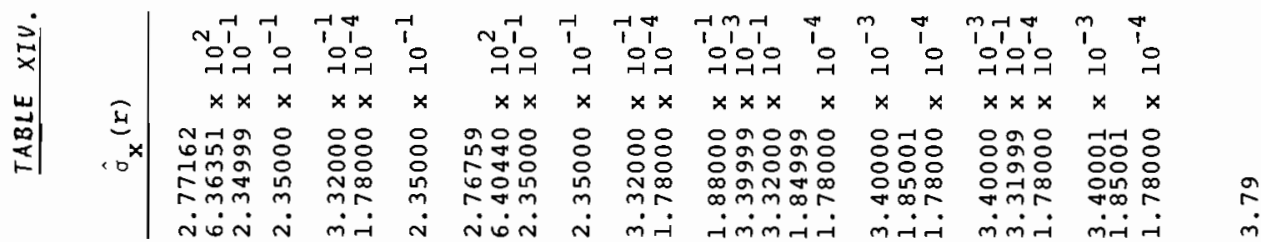

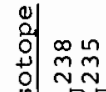

$\stackrel{\infty}{m}$

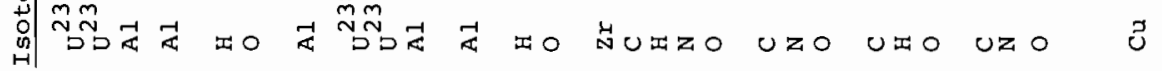

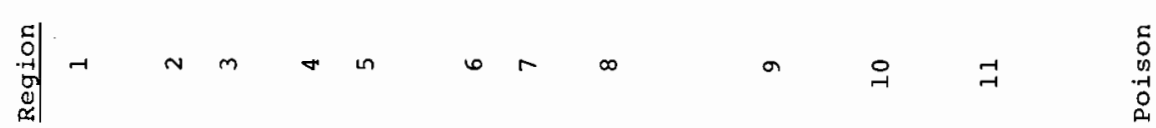


Therefore all non-l/v epithermal absorption is accounted for in the resonance escape probability $p_{\text {nonl/v }}$.

The equation relating the thermal utilizations in the poisoned and unpoisoned cells with $\mathrm{k}_{\infty}$ can be rewritten in terms of absorption rates:

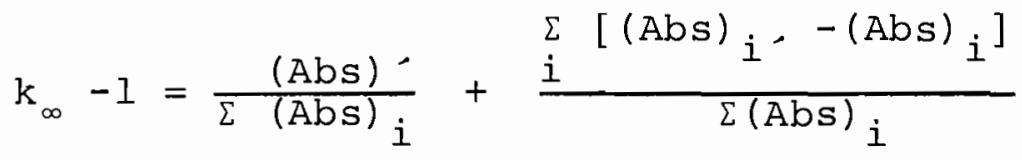

$(\mathrm{Abs})^{\prime}=$ relative $1 / \mathrm{V}$ absorption rate in copper poison.

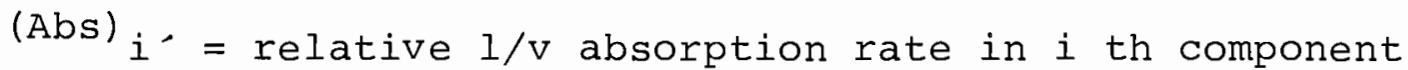
of the test cell with copper neutron absorber.

$(\mathrm{Abs})_{i}=$ relative $1 / \mathrm{V}$ absorption rate in the $i$ th component of the test cell without copper neutron absorber.

A condition in this equation is that the absorption rates in the fuel for the poison and unpoisoned case are normalized to be equal.

Valuesfor $k_{\infty}$ determined from this PCTR experiment are presented in Table I of the summary.

\section{$k_{\infty}$ DETERMINED FROM ADJOINT WEIGHTED} CROSS SECTION TECHNIQUE

\section{Adjoint Weighted Cross Section Parameters}

Information about neutron multiplication properties of a medium can also be obtained without having to add an absorber to the medium by measuring the adjoint weighted excess neutron production cross section, defined here as $\left\langle\Sigma_{p}\right\rangle(2,9)$. The infinite medium excess neutron multiplication factor, $k_{\infty}-1$, can then be obtained from the experimentally determined $<\Sigma_{\mathrm{p}}>$ by making an appropriate leakage dependent correction:

$$
k_{\infty}-1=\frac{\left\langle\Sigma_{\mathrm{p}} \mathrm{o}^{\mathrm{A}} 2 \mathrm{a} \mathrm{V}^{\operatorname{cell}}\right.}{\mathrm{A}_{2}^{\operatorname{cel} 1} \mathrm{~V}_{\mathrm{a}} \Sigma_{\mathrm{oa}}}+\mathrm{g}\left(\Delta \phi, \Delta \phi^{+}\right)+\frac{\tau^{2} \mathrm{~B}^{4}}{1+\tau \mathrm{B}^{2}}
$$


where the first term on the right hand side of the equation is the excess production per unit thermal absorption in the cell. The second term is a correction for any mismatch between the flux and/or the adjoint in the test cavity and the equilibrium flux and/or ajoint characteristic of the medium. Foil measurements indicated that flux mismatch was negligible in this experiment. The third term is a calculated correction for leakage.

The expression for $\left\langle\Sigma_{p}>\right.$ in terms of measured and calculated quantities, are

$$
<\Sigma_{\mathrm{p}}>=\frac{\Delta \rho_{\text {cell }}}{\Delta \rho_{\mathrm{a}}} \frac{\mathrm{V}_{\mathrm{a}} \Sigma_{\mathrm{oa}}}{\mathrm{V}_{\operatorname{cell}}} \frac{\mathrm{A}_{2 \mathrm{a}}+\rho_{1 \mathrm{a}}}{\mathrm{A}_{2 \mathrm{a}}^{\mathrm{s}}}
$$

This cross section is normalized to the $2200 \mathrm{~m} / \mathrm{sec}$ cross section of the absorber, $\Sigma_{o a}$; the same normalization of calculated values is necessary for comparison to measured values. The quantities are defined as follows:

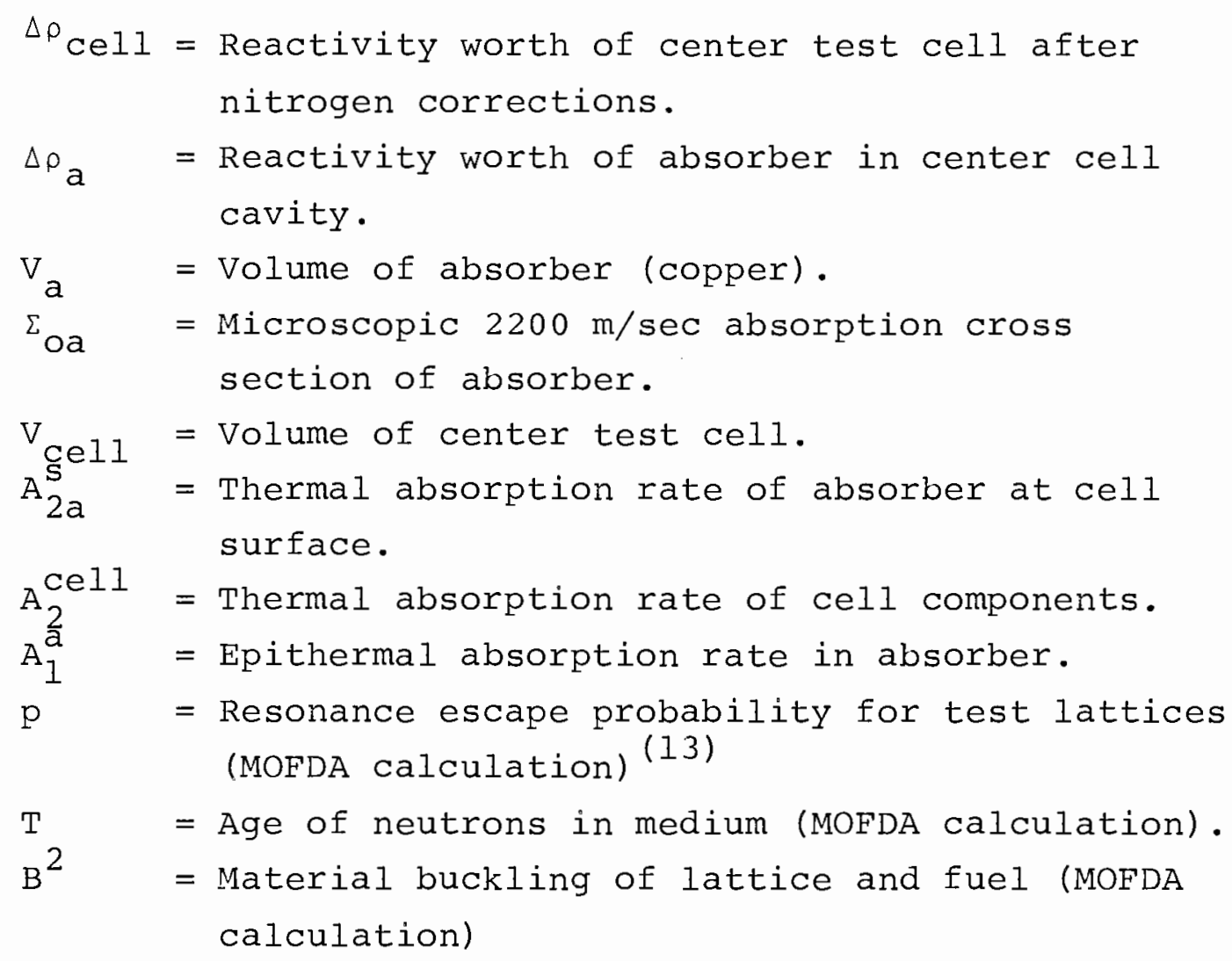


The adjoint weighted cross section technique was used to measure the infinite medium neutron multiplication factor of four different cell conditions.

Normal coolant case

Simulated flooding around process tube

Simulated flooding around process tube and in

gas vents

Dry cell case

Data and Resulting $k_{\infty}$

The measured parameters for the above conditions are listed in Table XV with the respective $\mathrm{k}_{\infty}$ calculations. For calculational ease a new quantity is defined for $k_{\infty}$; that is,

$$
\begin{aligned}
& \mathrm{k}_{\infty}=\frac{\left\langle\Sigma_{\mathrm{p}}>\right.}{\left(\Sigma_{\mathrm{a}}\right)_{0}^{\mathrm{cell}}}+\mathrm{g}\left(\Delta \phi, \Delta \phi^{+}\right)+\frac{\mathrm{T}^{2} \mathrm{~B}^{4}}{1+\mathrm{TB}^{2}} \\
& \text { where }\left(\Sigma_{\mathrm{a}}\right)_{0}^{\mathrm{cell}}=\frac{\mathrm{A}_{2}^{\mathrm{cell}} \mathrm{V}_{\mathrm{a}}^{\mathrm{s}}{ }^{\Sigma_{\mathrm{oa}}}}{\mathrm{A}_{2 \mathrm{a}}^{\mathrm{s}} \mathrm{V}_{\text {cell }}}
\end{aligned}
$$

if $\left(\Sigma_{a}\right)_{0}^{c e l l}$ is calculated by THERMOS as is done in the dry cell experiment when component absorption rates were not measured,

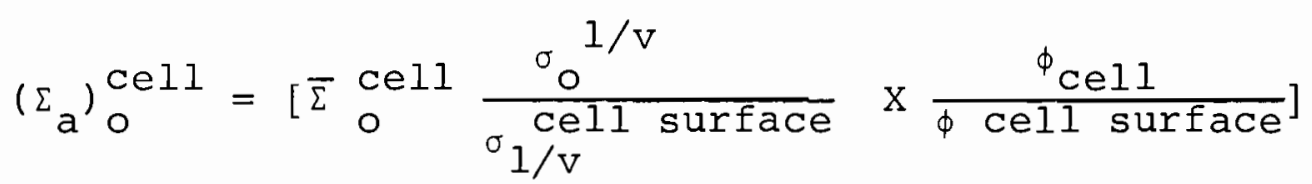

COMPARISON OF ACTUAL WATER FLOODING WITH SIMULATED FLOODING

\section{Description}

After all cell measurements had been completed in the PCTR, the center fuel channel and graphite bars were removed with the adjacent, surrounding graphite. This latter material was cut to permit the immersion of the center test cell and for the whole 


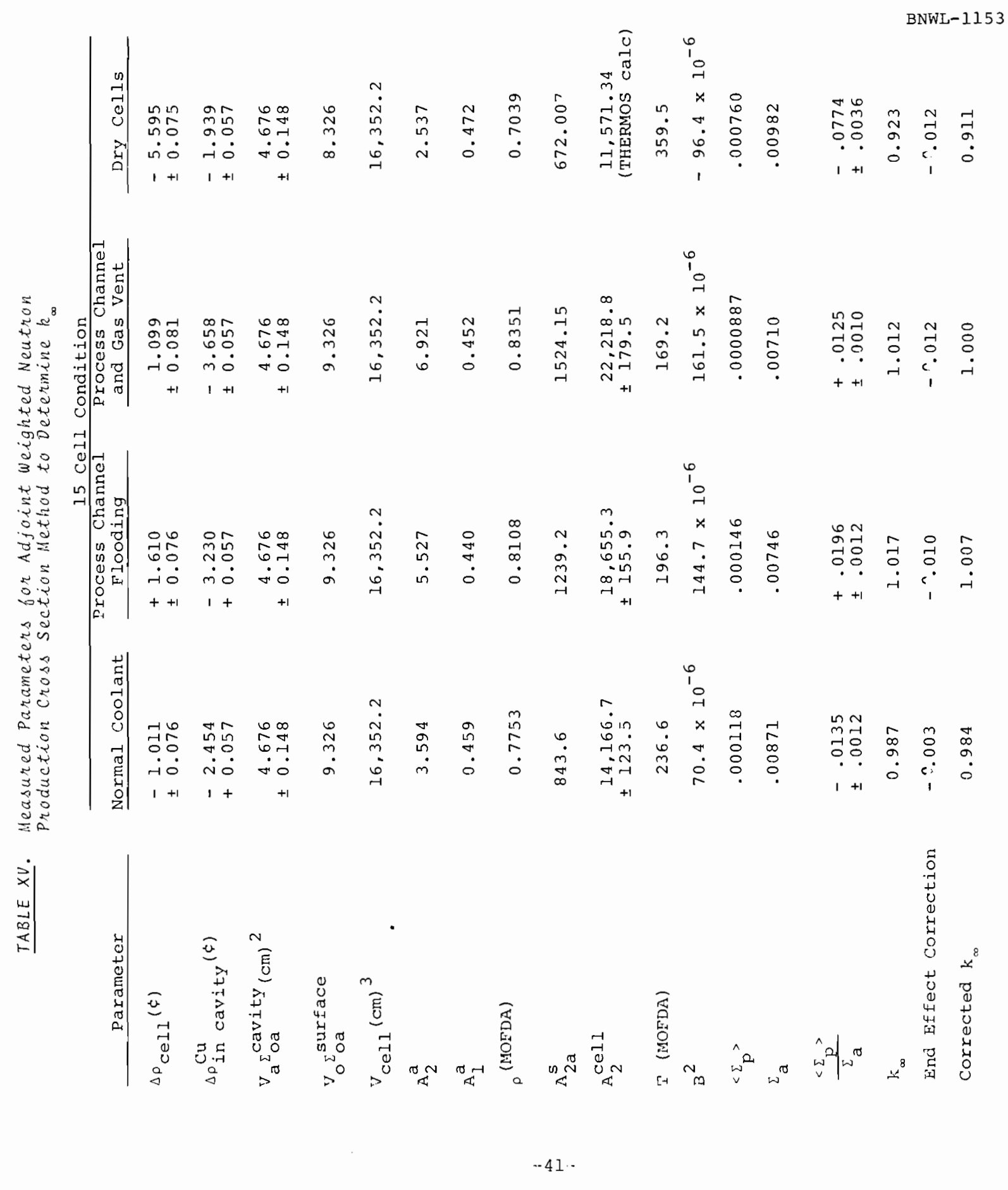


assembly (i.e., tank and center cell) to be inserted in the reactor. The center cell plus the tank with the separable element and foil holders are shown in Figure 14. The photograph is different than actually was the case since it shows the lucite and polyethlene wrap in place around the process tube and in the gas vents, respectively. The flooding simulators were not used in these measurements; the can was filled with water after inserting the graphite and fuel so that all the vents and area around the process tube would contain water. The reactivity measurements and foil irradiations were accomplished with water in the test cell.

Results

The statistics and measured results of the water flooded lattice are listed in Table XVI without too much explanation. The parameters have been defined in the sections above concerned with the normal coolant and simulated flooding conditions. It should be noted that only the center test cell could be flooded and simulated flooding conditions with polyethlene and lucite were used in all buffer cells and regions.

\title{
TABLE XVI. Statistics and Results of Actual water
} Flooding in PCTR Test Lattice

\author{
Thermal Utilization \\ $0.807 \pm 0.011$ \\ $\mathrm{k}_{\infty}$ (null reactivity measurement) \\ $0.967 \pm 0.003$ \\ $k_{\infty}$ (non-poison measurement) \\ $0.967 \pm 0.003$ \\ II (o) without tank and simulated \\ $+46 \pm 4$ gram copper \\ $M$ (o) with tank in place and \\ $+47 \pm 4$ gram copper \\ conditions \\ $M$ (o) with tank in place and \\ water flooding conditions \\ (buffer cells simulated \\ flooding with polyethlene \\ and lucite) \\ $(M(O)) I / V$ with tank in place and \\ - $98 \pm 2$ gram copper \\ conditions (buffer cells \\ simulated flooding with \\ polyethlene and lucite)
}




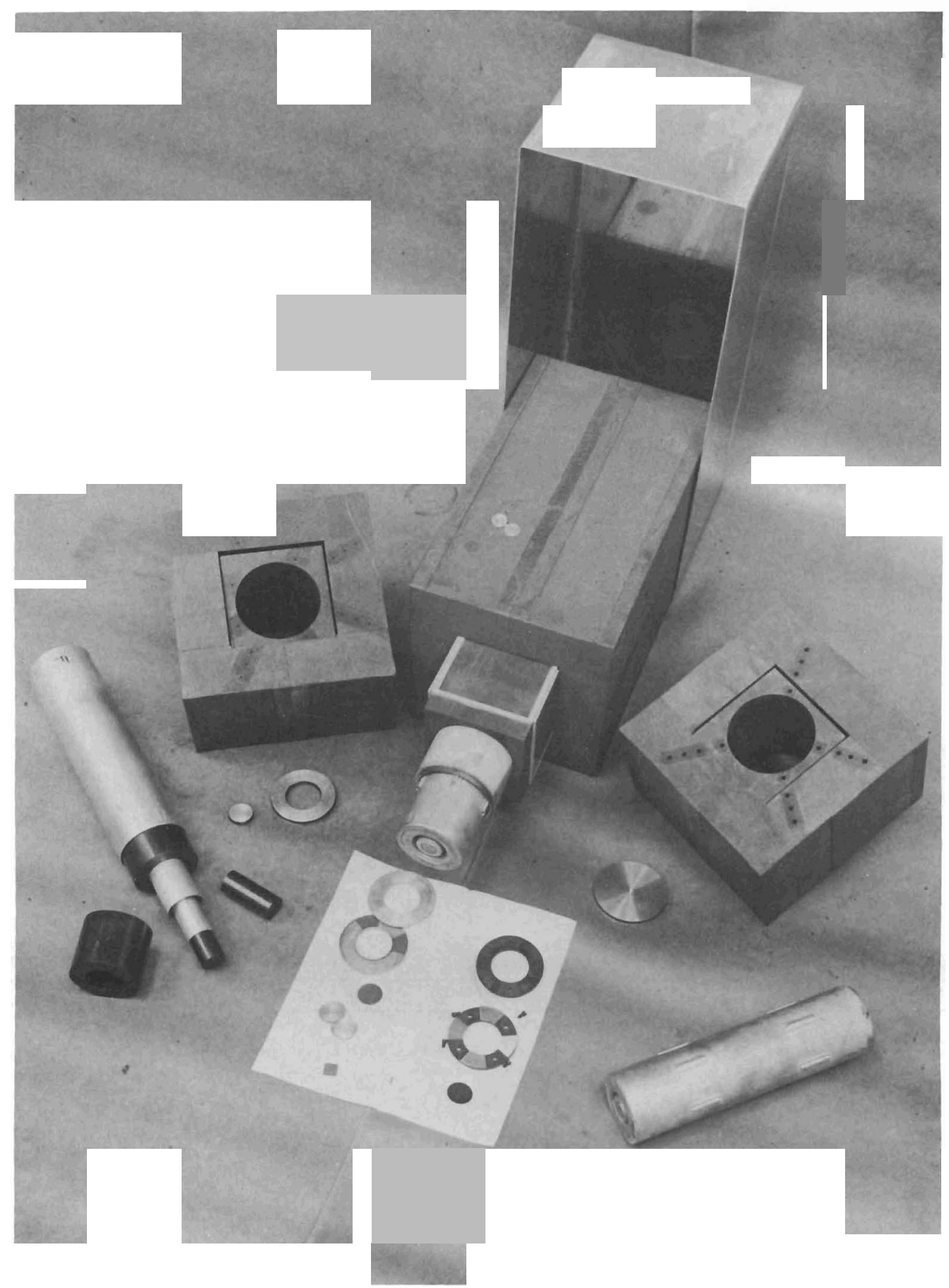

FIGURE 14. Center Cell and Aluminum Tank Used for the Experimental Measurement of Actual water Flooding Effects 
The measurements with actual water flooding was a one-shot attempt because the graphite immediately began to absorb the water and conditions in the center test cell did not remain constant.

After the reactivity measurements the experiment proceeded with the foil irradiations necessary to derive the neutron utilization of the cell components. Following the irradiations there was an attempt to return to original cell conditions before the water was added. At that time the graphite components of the center cell were weighed and then put into an oven to dry out. Following the drying period the components were reweighed with the following results:

\begin{tabular}{llc} 
Component & \multicolumn{1}{c}{ Condition } & Weight (grams) \\
Hole Bar & Before Flooding & $3,242.40$ \\
Hole Bar & Before Drying & $3,242.40$ \\
Hole Bar & After Drying & $3,242.25$ \\
Outer Bar & Before Flooding & $19,850.90$ \\
Outer Bar & Before Drying & $20,232.85$ \\
Outer Bar & After Drying & $19,836.90$ \\
Volume of Water Absorbed in Outer Bar & $395.95 \mathrm{cC}$.
\end{tabular}

Comparison of Sub-Cadmium Measured Activities with THERMOS Calculations for Water Flooded Conditions

There was no certainty of the absorption rate of water into the graphite so that the actual cell conditions which existed at the time of the foil irradiations. were not exactly known. Therefore the foil data was compared with the thermal flux traverses derived by two different THERMOS computer code calculations, one without water in the outer graphite and the other with $395 \mathrm{Cc}$ of water distributed in the outer graphite. The plots of these comparisons are graphed in Figures 15 and 16. These results indicate the water was probably in the outer graphite during the foil irradiations. Therefore the cross sections derived for the calculation of neutron utilization 


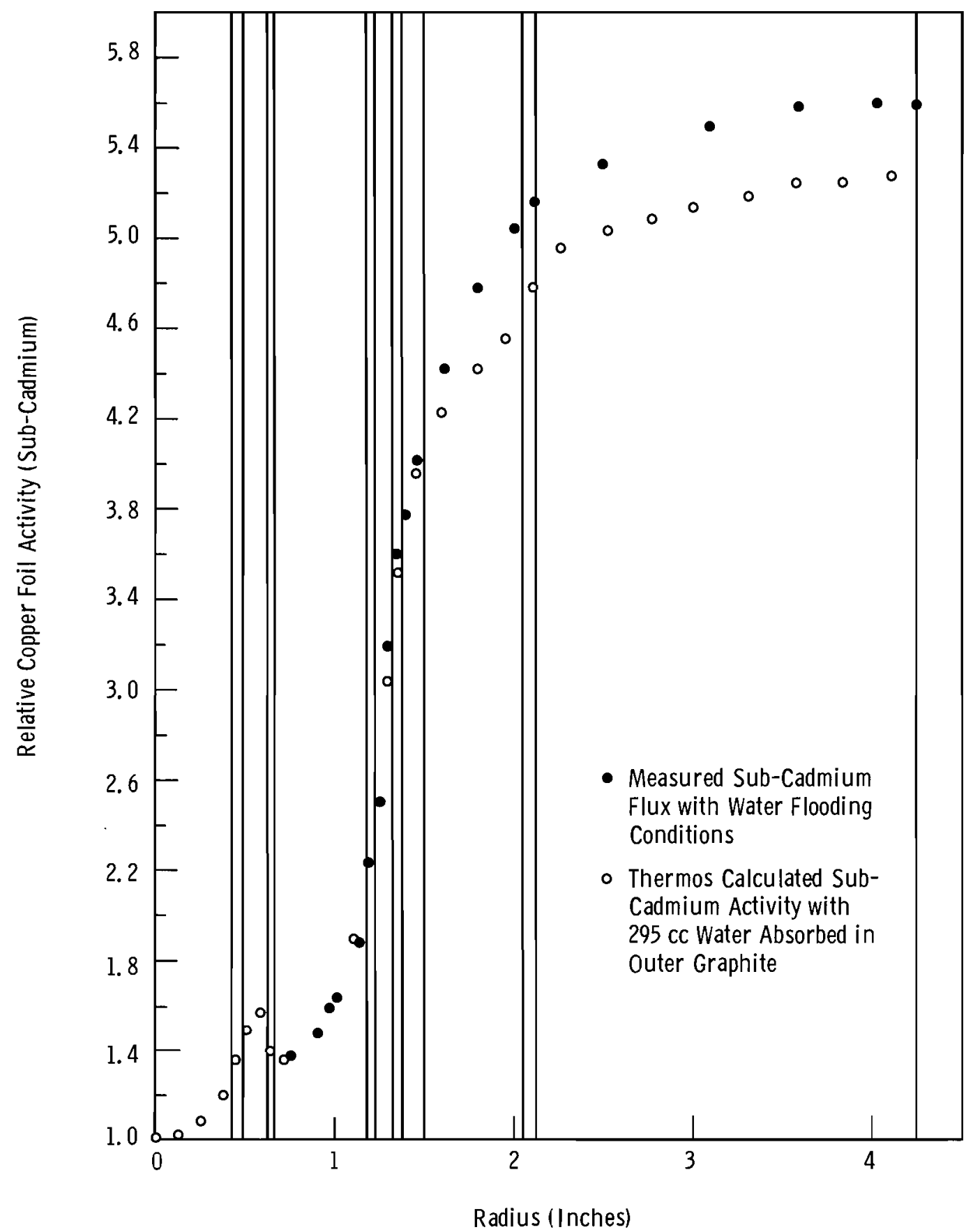

FIGURE 15. Radial Flux Plots Derived by Experiment and THERMOS calculations (Actual water Flooded Lattice and $395 \mathrm{cc}$ Water In outer Graphitel 
BNWL-1153

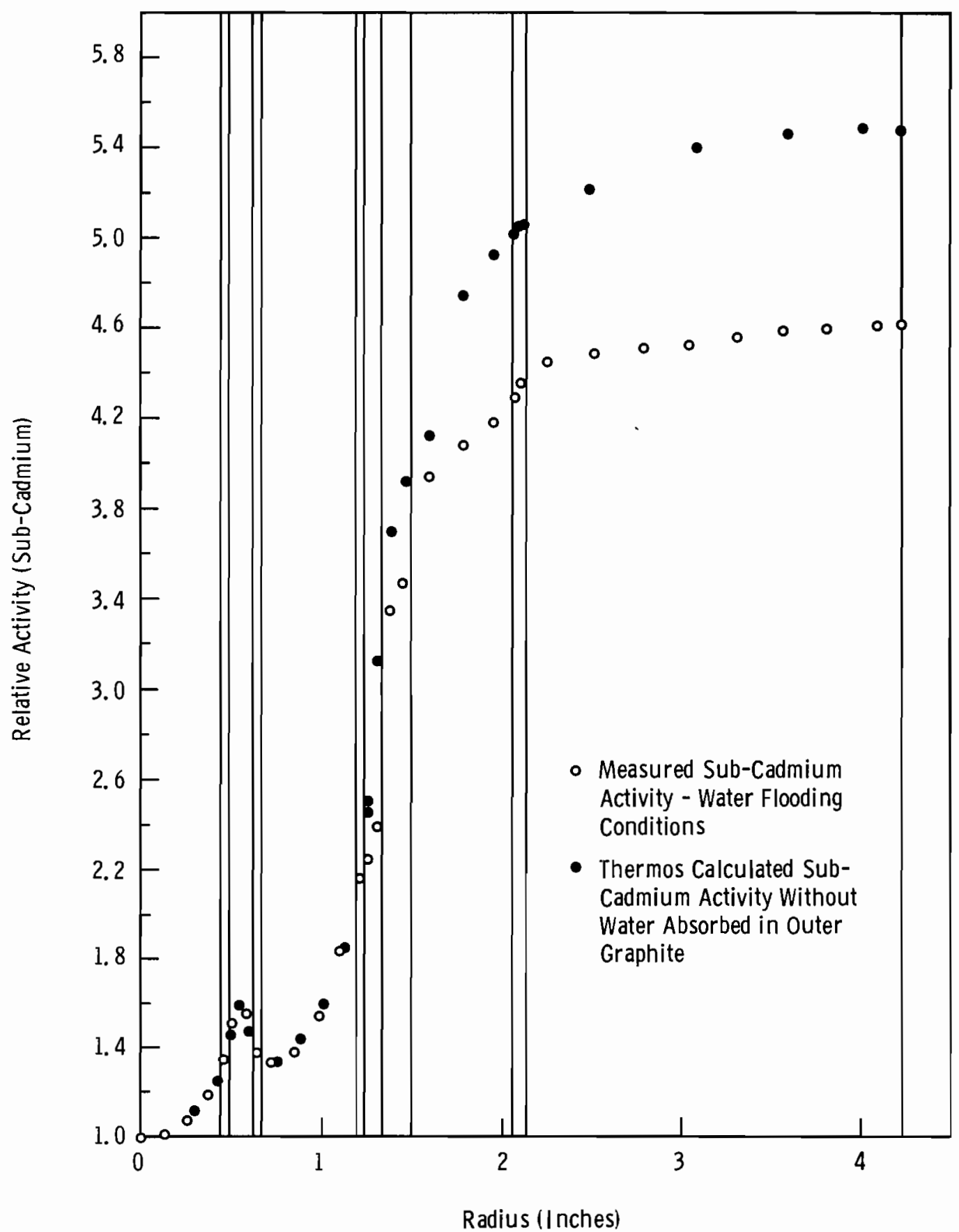

FIGURE 16. Relative Flux Plots Derived by Experiment and THERMOS Calculations (Actual water Flooded Lattice Without water Absorbed in Graphitel 
were taken from the THERMOS case with water in the outer graphite.

\section{Cross Sections and Utilizations}

The cross sections (Table XVII) necessary to derive the neutron utilization of the cell comporents were taken from the THERMOS calculation based on the condition that the outer graphite in the flooded lattice had absorbed 395 cc of water. The neutron utilization (Table XVIII) were calculated, based on the same assumption.

\section{TABLE XVII. Thermos calculated cross Sections}

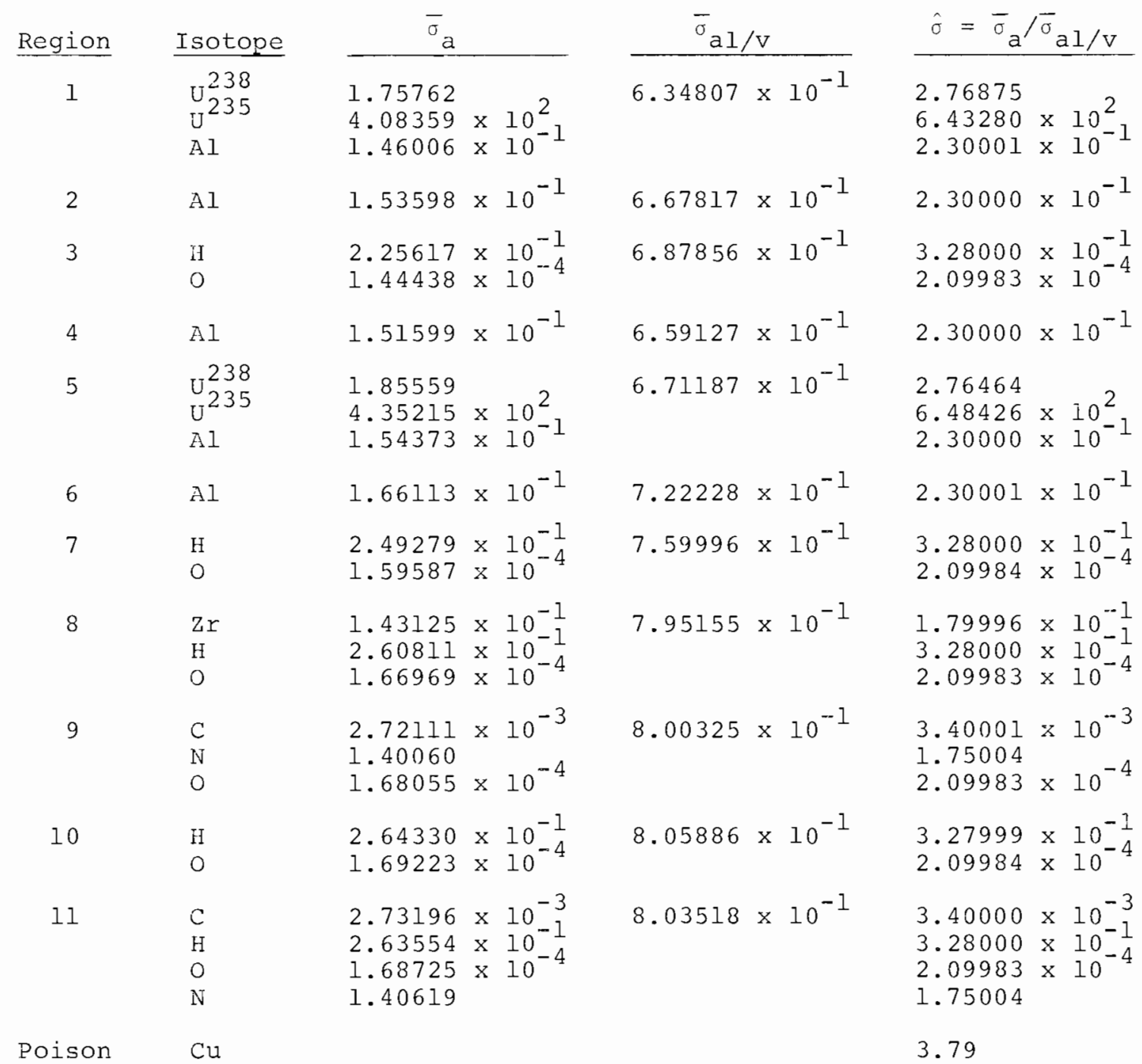


BNWL- 1153

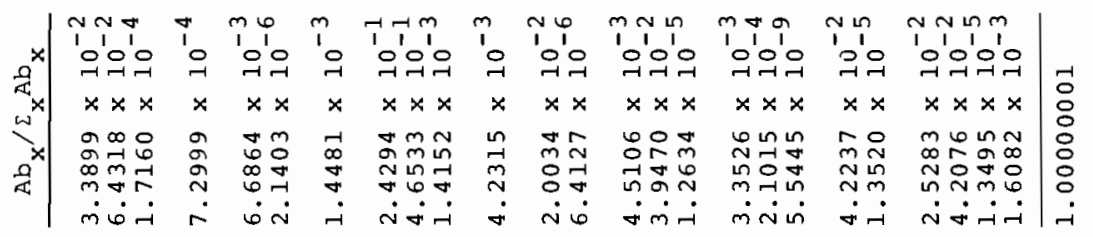

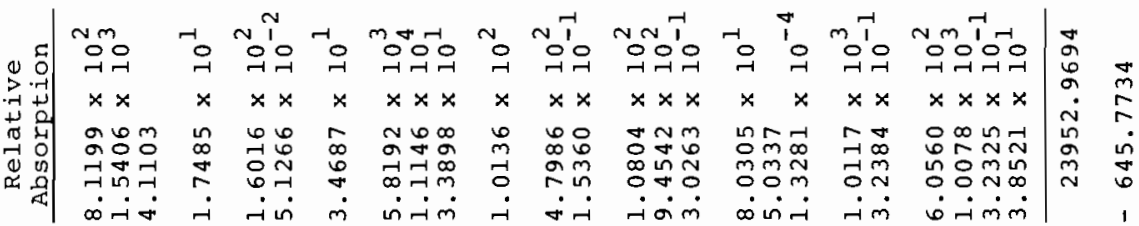

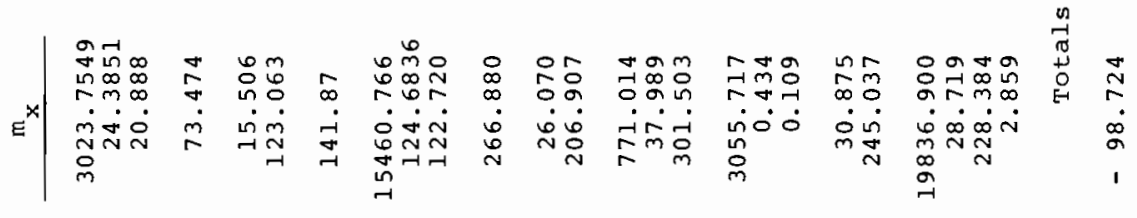

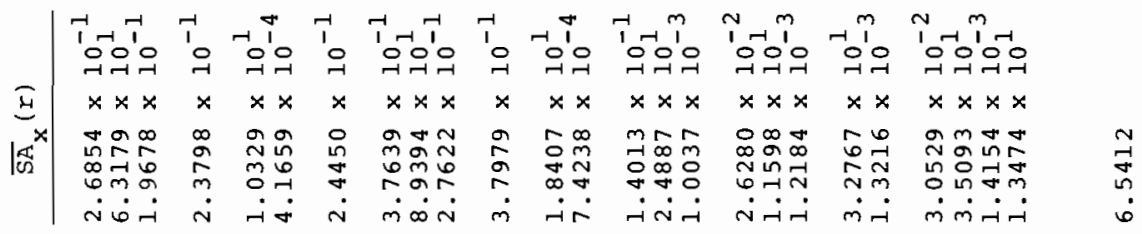

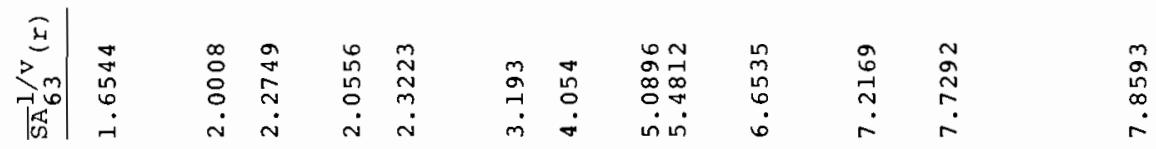

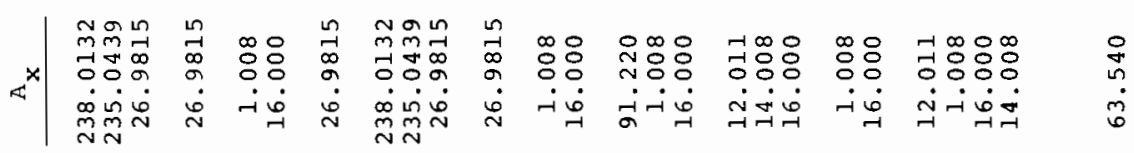

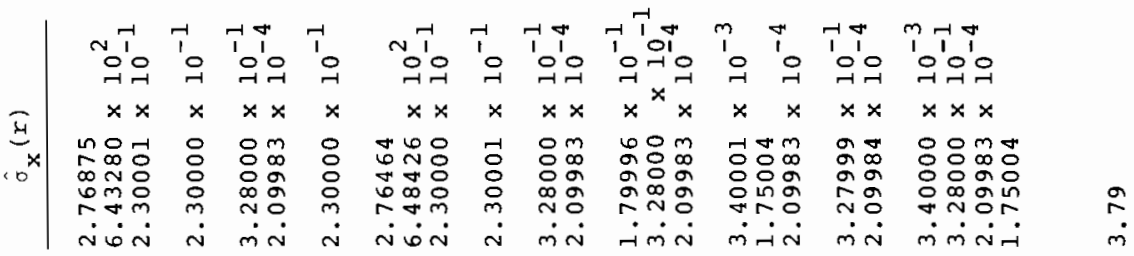

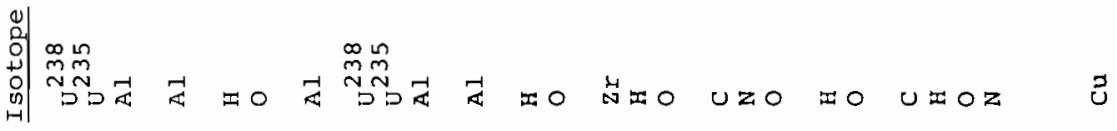

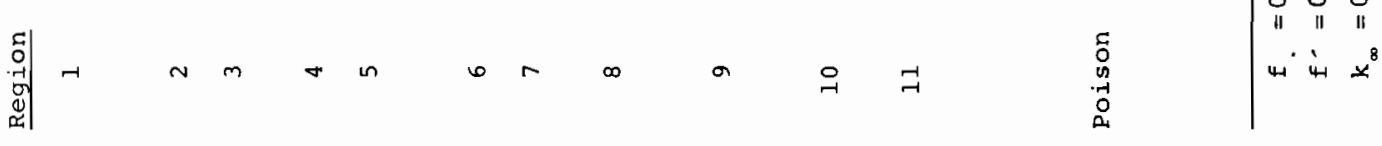




\section{APPENDIX A}

\section{Corrections and System Errors}

\section{A. Nitrogen Corrections}

Nitrogen affects the null reactivity values of the cells in two ways; air occupies the void spaces in the graphite and is a neutron absorber, and when the center cell is removed, ambient air enters and fills the cavity. The measured values of $\mathrm{k}_{\infty}$ for the supercell in the PCTR are for such a lattice stacked in an air environment. To obtain the values of $\mathrm{k}_{\infty}$ for these lattices stacked in a vacuum environment (or helium), the effect of the $1 / \mathrm{v}$ utilization of nitrogen in the cell (Tables XII, XIII, XIV and XVII) should be removed. The change is approximately $2.0 \mathrm{mk}$ in normal coolant conditions.

The determination of the reactivity worth of the nitrogen, which fills the cavity formed by removal of the central supercell, $\Delta \rho_{N^{\prime}}$ is inferred from a copper sensitivity, $\mathrm{S}_{\mathrm{Cu}}^{\mathrm{Cavity}}$, measured value using the expression:

$$
\Delta \rho_{N}=D C \frac{p}{T}\left(M_{N}\right)(1-C) S_{C u}^{\text {Cavity }}
$$

where $D=$ thermal disadvantage factor for the thickness of copper used in the determination of $\mathrm{S}_{\mathrm{Cu}}^{\mathrm{Cavity}}=$ 1.0110 .

$\mathrm{S}_{\mathrm{Cu}}^{\text {cavity }}=\Delta \rho_{\mathrm{Cu}}^{\text {cavity }} / \mathrm{M}_{\mathrm{Cu}}^{\text {cavity }}=\xi /$ gram of copper

$\Delta \rho_{\mathrm{Cu}}^{\text {cavity }}=$ reactivity worth $(\xi)$ of mass of copper, $\mathrm{M}_{\mathrm{Cu}}^{\text {cavity }}$, in the supercell cavity

$\mathrm{p}=$ atmospheric pressure during reactivity measurement, mb;

$\mathrm{T}=$ ambient temperature in the cavity, ${ }^{\circ} \mathrm{K}$ 
$M_{n}=$ mass of nitrogen (at standard temperature and pressure) $=16.72 \mathrm{~g}$

$C=\frac{\sigma_{0}^{N}}{\sigma_{0}^{C u}} \frac{A^{C u}}{A^{N}} \frac{T_{0}}{P_{0}}$

$\sigma_{0}^{N} \quad=2200 \mathrm{~m} / \mathrm{sec}$ microscopic absorption cross section of nitrogen $=1.88$ barns

$\sigma_{\mathrm{O}}^{\mathrm{Cu}}=2200 \mathrm{~m} / \mathrm{sec}$ microscopic absorption cross section of natural copper $=3.79$ barns

$\mathrm{A}^{\mathrm{Cu}}, \mathrm{A}^{\mathrm{N}}=$ copper and nitrogen atomic weights

$T_{O}, P_{O}=$ standard temperature and pressure

The quantity $(1-C)$ is a correction for the non-1/V nature of the epi-thermal energy dependance of the absorption cross section of natural copper, approximated by:

$$
1-C=1-\frac{m_{1}}{m_{2}} \frac{R_{e x}^{C u}}{R_{e p i-C d}^{C u}(\operatorname{Cdr}-1)},
$$
where $\frac{\mathrm{m}_{1}}{\mathrm{~m}_{2}}=$ ratio of the fast-to-thermal adjoint fluxes and probability of the test lattice $=0.7753$ as calculated with MOFDA (13).

$$
\begin{aligned}
\mathrm{RI}_{\mathrm{ex}}^{\mathrm{Cu}=} & \text { effective excess resonance integral of natural } \\
& \text { copper for the thickness of copper used in } \\
& \text { measuring } \mathrm{S}_{\mathrm{Cu}}^{\mathrm{Cu}} \mathrm{ty}=1.3705 \mathrm{~b} .
\end{aligned}
$$

$\mathrm{RI}_{\text {epi-Cd }}^{\mathrm{Cu}}=$ effective epi-cadmium resonance integral of natural copper for the thickness of copper used in measuring $\mathrm{S}_{\mathrm{Cu}}^{\text {cavity }}=2.8805 \mathrm{~b}$.

CdR = cadmium ratio of copper in the cavity, for the thickness of copper used in measuring $\mathrm{S}_{\mathrm{Cu}}^{\mathrm{cavity}}$ 
$\mathrm{CdR}$

$$
\begin{aligned}
& =9.188 \text { for normal coolant conditions } \\
& 13.535 \text { for simulated flooding conditions } \\
& \text { around process tube } \\
& 16.255 \text { for simulated flooding conditions } \\
& \text { around process tube and gas vent } \\
& 6.379 \text { for dry cell conditions }
\end{aligned}
$$

B. $1 / \mathrm{v}$ Mass Equivalent of Copper

The requirement that the material used as absorber in the determination of $k_{\infty} l / v$ have an effective cross section that varies as $1 / \sqrt{\mathrm{E}}$, makes it necessary to define a $1 / \mathrm{V}$ equivalent mass of copper, ${ }^{\mathrm{H}} 1 / \mathrm{V}$, so that its reactivity coefficient is equivalent to the correct mass of copper, $10^{\circ}$

$$
\mathrm{M}_{1 / v} \mathrm{SA}_{1 / v} \mathrm{M}_{2}=H_{0}\left(\mathrm{SA}_{1 / v} \mathrm{M}_{2}+\mathrm{SA}_{\left.\operatorname{res}^{\mathrm{M}_{1}}\right)}\right.
$$

Account is taken of the worth of epi-thermal resonance absorptions in copper relative to the worth of $1 / \mathrm{v}$ absorptions. As shown in the previous notation,

$$
{ }^{i i} 1 / v=H_{0}\left[1+\left(\frac{m}{m_{2}}\right)\left(\frac{R I_{e x}^{C u}}{C d R \cdot R I_{e p i-C d}^{C u}-R I_{e x}}\right)\right]
$$

For this experiment 0.010 inch thick copper strips were placed at the boundary of the cell and foils were placed in these strips. The effective resonance integrals were taken from measurements by Bennett ${ }^{(16)}$. Values for $M_{1 / V}$ are only a few percent greater than $M_{O}$ and are listed in Table II.

C. Counter Efficiency for Dissected Foils

The irradiated copper foils used to measure the relative reaction rates in the fuel had a specific 
activity which was a function of radial symmetry, primarily due to disadvantage factors in the fuel. The distribution of the activity in a detector foil affects the over-all efficiency of the scintillation counting system, because the counter system varies with distance from the center of the crystal. Copper foils irradiated in the external thermal column of the PCTR have a constant specific activity with respect to the radial symmetry. Therefore a counter efficiency factor must be removed from the measured data in order to obtain relative reaction rates in the fuel.

The method of correction was developed by Newman (14) using data measured by Bennett as follows:

The observed specific activity for a given geometry shaped detector foil at a given height above the crystal can be expressed as the specific activity of the detector foil with respect to its radial symmetry and counter efficiency which is also a function of radial position.

$$
\overline{\mathrm{SA}}_{\text {observed }}=\{\mathrm{SA}(\mathrm{R})\} \times\{\Sigma(r)\}
$$

Counter efficiency measurements with a Cs-137 pin point source were made by $R$. A. Bennett (15) to determine the relative efficiency of the counter as a function of distance between the pin-point source and the center of the surface of the scintillation crystal.

The quadrant and sector foils used in the fuel rod and tube respectively, were dissected into small annular regions. By super position of the annular regions on the counter efficiency topographical plot, an effective counter efficiency for reach region is obtained,

$$
\varepsilon_{R}=\frac{\delta_{r}(r) d A}{\delta_{r} d A}
$$


where $\varepsilon_{R}=$ counter efficiency at a distance $r$ from the center of the surface of the crystal

$$
\begin{aligned}
\mathrm{dA}= & \text { element of area on the foil at a distance } r \\
& \text { from the center of the crystal. }
\end{aligned}
$$

Each section of the dissected foil was counted in the position that it would normally assume had the whole foil been placed on the crystal. The corrected activity for that dissected piece is

$$
S A_{R} \text { (corrected) }=\frac{S_{R} \text { (observed) }}{\varepsilon_{R}}
$$

D. Flux Enhacement by Detectors

Three dimensional Monte Carlo calculations by F. E. Dunn explicitly including foils have indicated that the flux in a foil is often considerably different from the flux in the medium in which it is placed, even for optically thin foils in which no such effect would be expected. A correction must be applied to the measured foil activities to obtain the proper flux averages to be used in determining the thermal disadvantage factors.

The derivation for the fraction of the measured foil activity that is due to flux peaking in a flat foil of thickness $t$, and diameter or width $L$, was reported in reference (9) and is summarized as follows:

If a foil of macroscopic absorption cross section

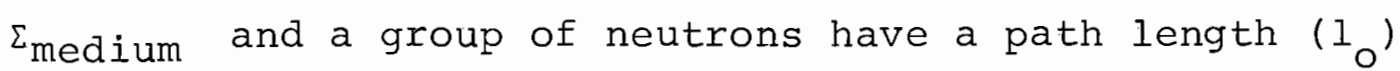
chrough the foil, then their contribution to the activation of the foil, $A_{\text {foil }}$, is $1_{0} \Sigma_{\text {foil }}$. The fractional flux peaking in the foil is $1_{0}\left(\Sigma_{\text {medium }}-\Sigma_{\text {foil }}\right)$ if $1_{0} \Sigma_{\text {foil }}$ and $1_{0} \Sigma_{\text {medium }}$ are small compared to 1 . Therefore if $A_{0}$ is the activation that would occur if the flux in the foil were the same as the flux in the medium, 


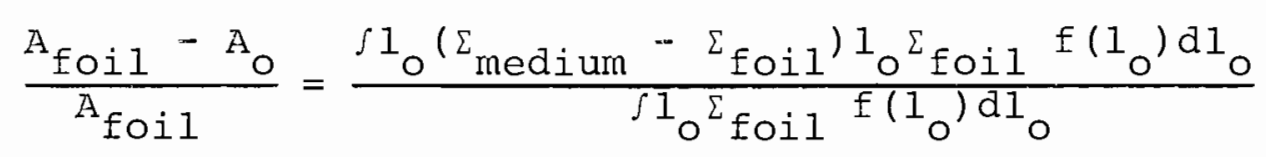

where $f\left(1_{0}\right)$ is the probability of the occurrence of $1_{0}$. If $\theta$ is the angle of incidence between the neutron path and the foil surface, then

$$
1_{0}=\frac{\tau}{\sin \theta}, \text { for } \theta>\frac{\tau}{\bar{L}}
$$

For an isotropic flux, neglecting edge effects

$$
E\left(1_{0}\right) d R_{0}=\sin \theta \cos \theta d \theta
$$

so that the result gives:

$$
\frac{A_{\text {foil }}-A_{O}}{A_{\text {foil }}}=\tau\left(\Sigma_{\text {medium }}-\Sigma_{\text {foil }}\right) \ln (\mathrm{L} / \mathrm{t})
$$

The sub-cadmium activities of 0.010 inch thick copper foils were corrected by the use of this equation derived with average cross sections calculated by THERMos ${ }^{(10)}$.

\section{E. Central Cell End Effects}

When the central cell is removed from the test lattice in the course of obtaining the null reactivity measurements, both the front and rear end buffers have one end of their process tubes exposed to the central cell cavity. This exposure could affect the reactivity measurement of the cell-out conditions if there is sufficient neutron streaming to these ends. Therefore, the effects were partially measured during this experiment and correlated with three dimensional calculations from the computer code DOTSN $(16)$ to derive corrections for the measured data.

The measurement of the end effects was based on the fact that decreasing the length of the supercell will increase the solid angle of the central cavity seen by the exposed 
portion of the end buffer. The end buffer was switched with the center cell during one of the reactivity measurements in order to determine the reactivity affect of the cavity as a function of its length.

Reactivity worths of copper $(14.538 \mathrm{gm} /$ inch of center cell for the short cell and $20.518 \mathrm{gm} /$ inch for the normal test cell) were obtained and used: with the DOTSN calculations to extrapolate to the actual effect of the neutron streaming on the infinite multiplication factor measurements. The corrections which were applied to the measured $\mathrm{k}_{\infty}$ values are listed as: follows:

TABLEXIX. Corrections to $k_{\infty}$ for cell End Effects

Cell Conditions

Normal coolant

simulated process channel

flooding

Simulated process channel and gas vent flooding

Actual water flooding

Dry cell $\mathrm{k}_{\infty}$ Correction

$-2.85$

- 9.90

$-10.90$

$-5.80$

$-11.73$ 


\section{BNWL- 1153}

14. D. F. Newman, "PCTR Measurement of.k for Uranium Lithium Supercel1," BNWL-622, December 20, 1967.

15. R. A. Bennett, Private Communication.

16. F. R. Mynatt, "Users Manual for DOT," K-I694. 


\section{I $\underline{\mathrm{S}} \underline{\mathrm{T}} \underline{\mathrm{R}} \underline{\mathrm{I}} \underline{\mathrm{B}} \underline{\mathrm{U}} \underline{\mathrm{T}} \underline{\mathrm{I}} \underline{\mathrm{O}} \underline{\mathrm{N}}$}

Battelle-Northwest

$$
\begin{aligned}
& \text { C. L. Bennett } \\
& \text { J. E. Choate } \\
& \text { D. E. Christensen } \\
& \text { E. C. Davis, Jr. } \\
& \text { F. G. Dawson } \\
& \text { G. E. Hanson } \\
& \text { W. I1. Harris } \\
& \text { H. L. Henry } \\
& \text { J. H. Lauby } \\
& \text { E. D. Lippincott, Jr. } \\
& \text { T. J. Oakes } \\
& \text { D. R. Oden } \\
& \text { C. R. Richey } \\
& \text { L. C. Schmid } \\
& \text { G. D. Seybold } \\
& \text { R. I. Smith } \\
& \text { I. N. Sorrells } \\
& \text { V. O. Uotinen } \\
& \text { A. D. Vaughn (6) } \\
& \text { W. P. Walsh } \\
& \text { I. D. Williams }
\end{aligned}
$$

Battelie Memorial Institute (3)

Fechnical Information Files "(3)

Douglas United Iuclear

T. A. Ambrose

G. F. Bailey

P. A. Chitwood

G。C. Fullmer

P. D. Gross

I. L. Grumme

J. D. Tuthrie

J. P. Hamric

$\mathrm{J}, \mathrm{R}$. Langton

R. H. Meichle

R. L. Miller

W. S. Nechodom

J. F。 Nemic

R. Nilson

G. F。 Ows ley

I. I. Rash

I. Thierer

$\mathrm{H}$ 。 Toffer

F. H. Bouse (3)

$\underline{A E C-R L}$
AEC, Chicago Patent Group

$$
\begin{aligned}
& \text { G. H. Lee } \\
& \text { R. K. Sharp }
\end{aligned}
$$

AEC Division of Technical Information Extension (5) 